ORNL/TM-2001/65, Rev. 2

\title{
Nuclear Materials Identification System Operations Manual
}

\author{
Oak Ridge National Laboratory \\ Instrumentation and Controls Division \\ Advanced Nuclear Measurements and Control
}

L. G. Chiang

A. C. Gehl

J. K. Mattingly

J. A. McEvers

J. T. Mihalczo

J. A. Mullens

R. B. Oberer

August 29, 2001 


\section{Contents}

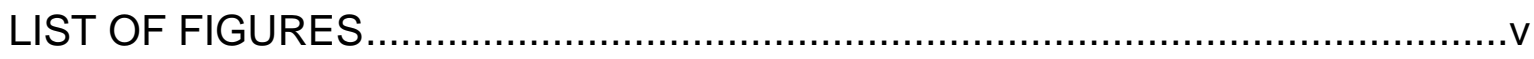

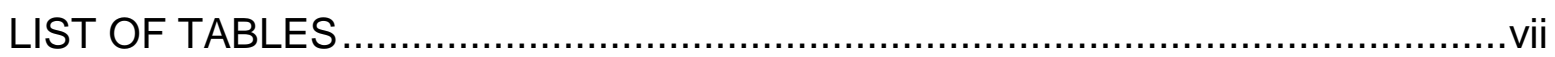

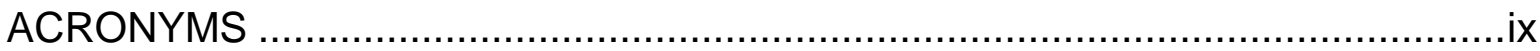

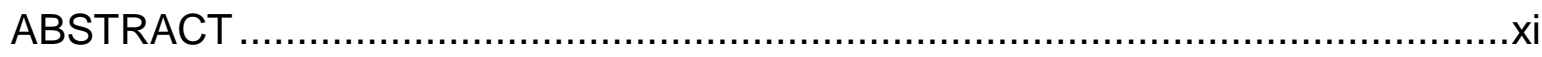

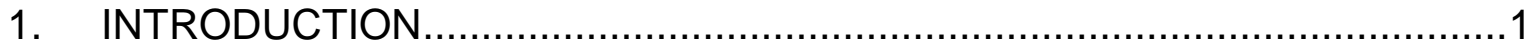

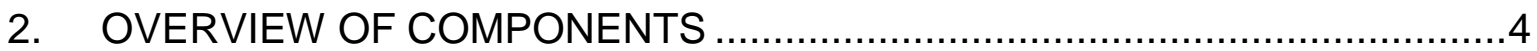

2.1 NMIS Processor and Power Supply..............................................

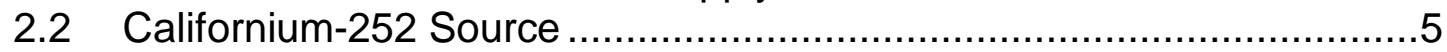

2.3 Ionization Chamber Amplifier ...................................................

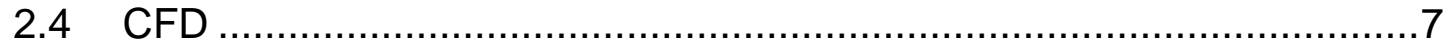

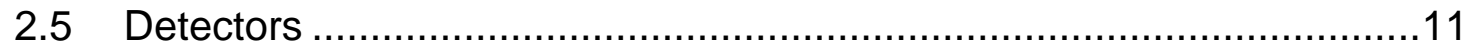

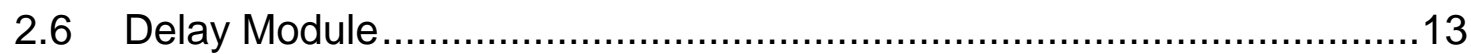

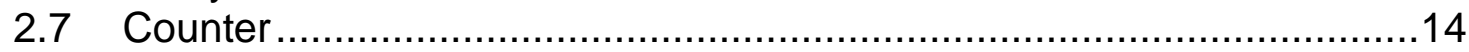

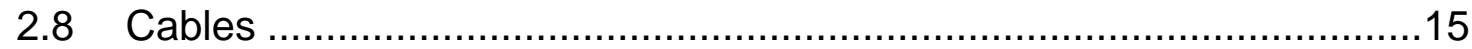

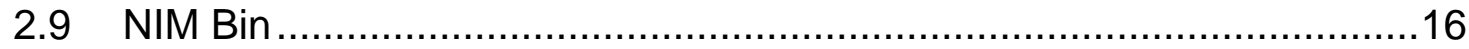

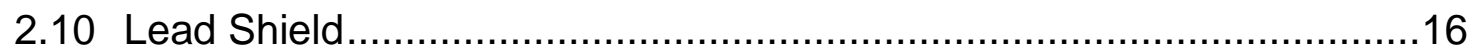

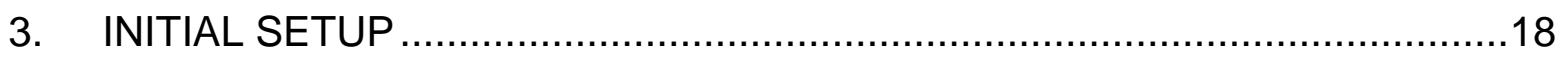

3.1 Installation of NMIS Processor ..................................................

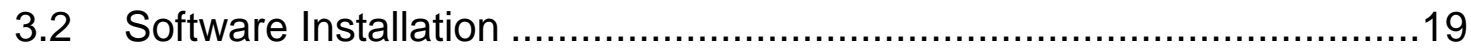

3.2.1 Installation of NT Board Driver ............................................19

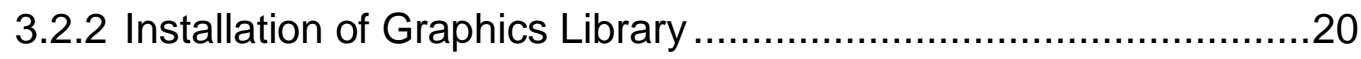

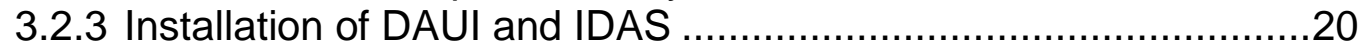

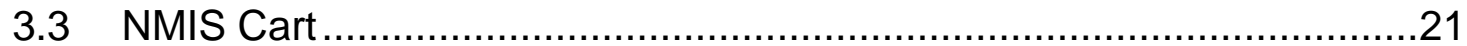

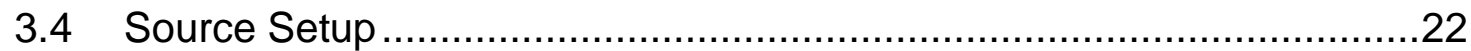

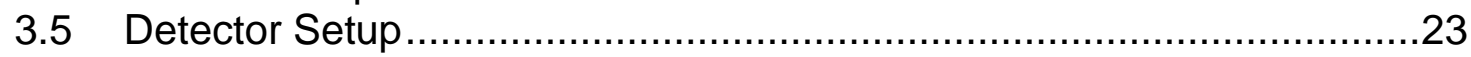

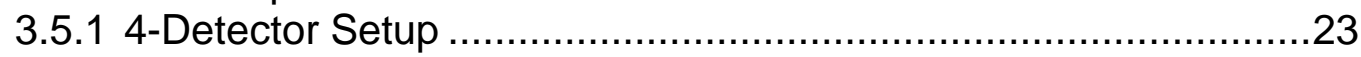

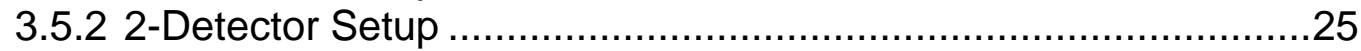

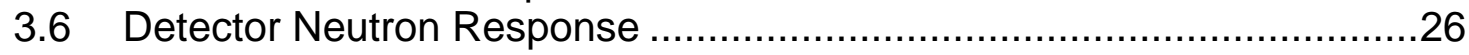

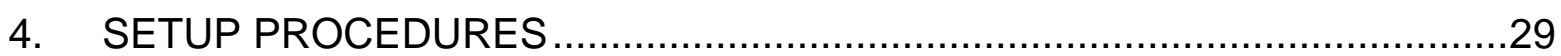

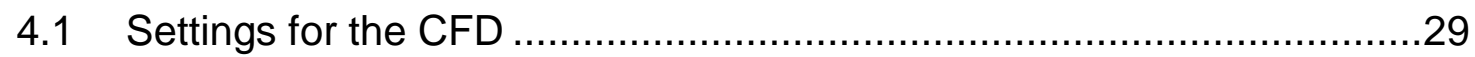

4.1.1 External Delay Cable......................................................29

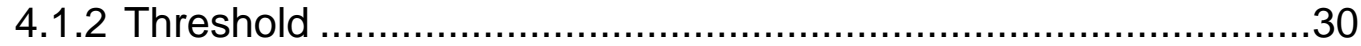

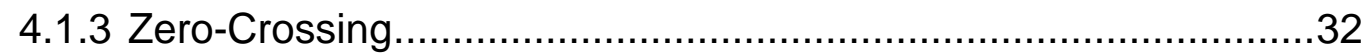

4.1.4 Pulse Width ....................................................................

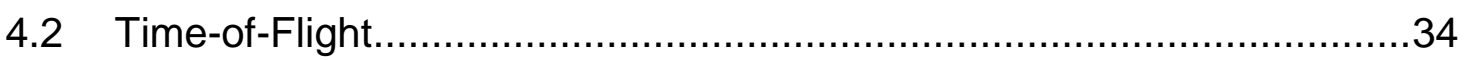

4.2.1 Verification of Gamma Peak Locations ....................................34

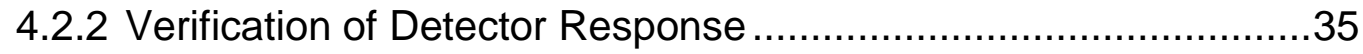




\section{Contents (Cont'd.)}

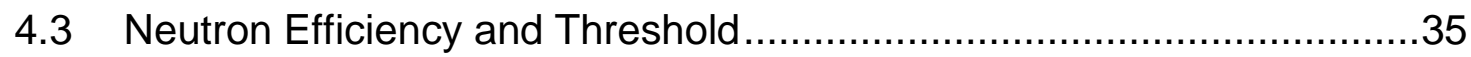

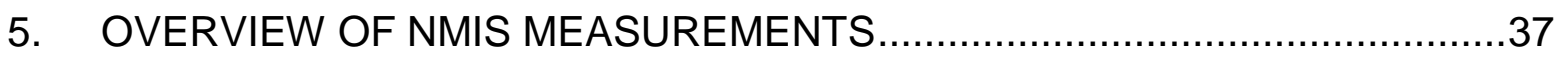

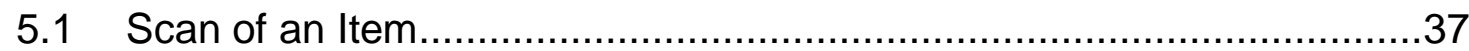

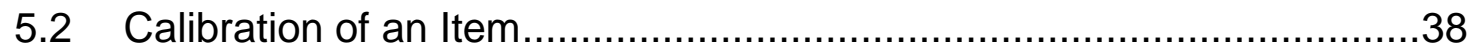

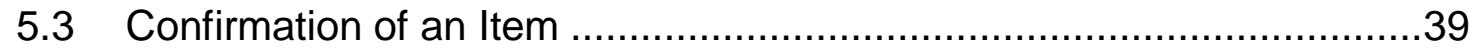

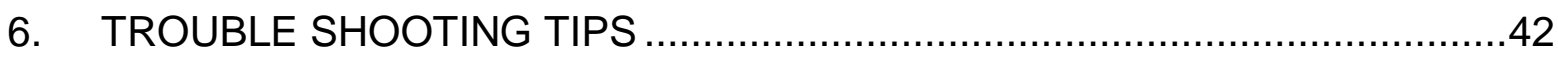

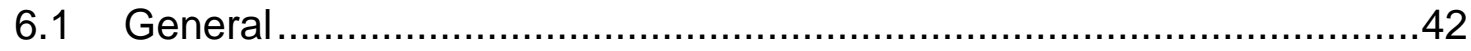

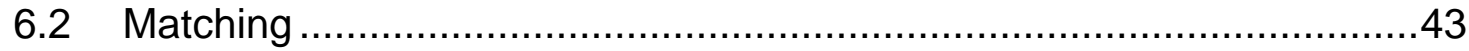

Appendix A. The Effect of Voltage and Discriminator Level on Detection Efficiency........48

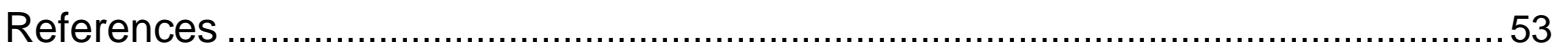




\section{LIST OF FIGURES}

1.1 Block Diagram of Detector Systems for NMIS ..........................................

2.1 View of NMIS Board Set From Rear of Computer ...........................................

2.2 Front View of External Power Supply for NMIS Board Set ...............................

2.3 Schematic of ${ }^{252} \mathrm{Cf}$ Parallel Plate lonization Chamber .........................................6

2.4 ORNL Designed Amplifier of ${ }^{252} \mathrm{Cf}$ Ionization Chamber ...................................... 7

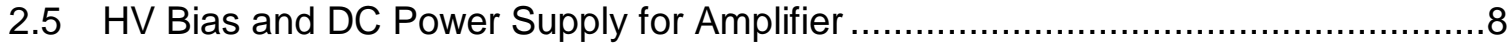

2.6 ORTEC Quad Constant Fraction Discriminator ........................................... 10

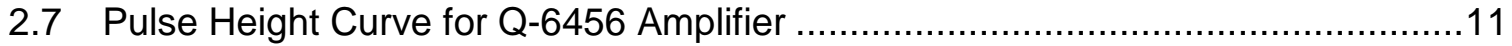

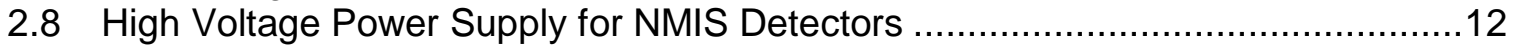

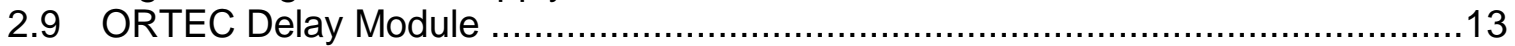

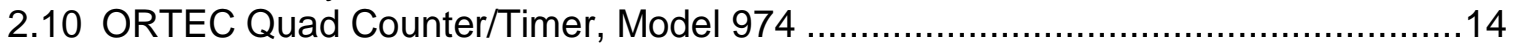

2.11 Two-Detector Stack in Lead Shield ........................................................... 17

2.12 Four-Detector Stack in Lead Shield ............................................................. 17

3.1 NIM Bin Configuration.............................................................................. 21

$3.2{ }^{252} \mathrm{Cf}$ Source Connections for Either Receipts or Inventory Measurements ...........23

3.3 Detector Connections for all Receipts Measurements ........................................24

3.4 2-Detector Connections for Temporary 2-Detector Setup.................................25

3.5 2-Detector Connections for 2-Detector Setup................................................26

3.6 Time-of-Flight Setup to Determine Detector Efficiencies ..................................27

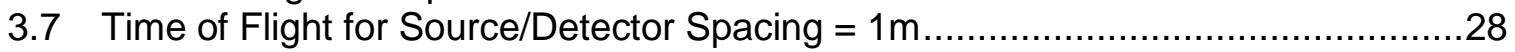

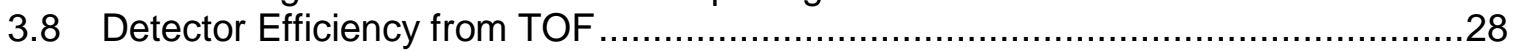

4.1 Measurement of $20 \%$ to $100 \%$ Rise Time of Detector Pulse ...............................30

4.2 Source Connections to Generate Pulse Height Curve...........................................31

4.3 Pulse Height Curve for ${ }^{252} \mathrm{Cf}$ Source and Q6456 Amplifier ..................................32

4.4 Monitor Pulses Crossing the Baseline at the Same Point .....................................33

5.1 Generic Source/Detector Setup for Scan of Containerized Item.........................38

5.2 Generic Source/Detector Setup for Calibration Measurements ............................39

5.3 Formation of a Reference Catalog ..................................................... 40

6.1 Axial Scan of the Container...........................................................................

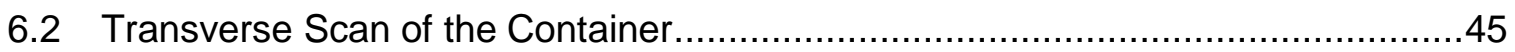

6.3 Polar Scan of the Container ........................................................................

A.1 Time of Flight for Source and Detector for Different CFD Levels: 30, 60, and $100 \mathrm{mV}$

A.2 Time of Flight for Source and Detector for Different Voltages: 1500, 1550, and $1600 \mathrm{~V}$

A.3 Neutron Peak Area and Photon Peak Area as a Function of CFD Level (mV) and Voltage (V)

A.4 Maximum Neutron Efficiency and Neutron Energy Threshold as a Function of CFD Level $(\mathrm{mV})$ and Voltage $(\mathrm{V})$..... 


\section{LIST OF TABLES}

1.1 Subset of NMIS Signatures for Five Input Channels .....................................

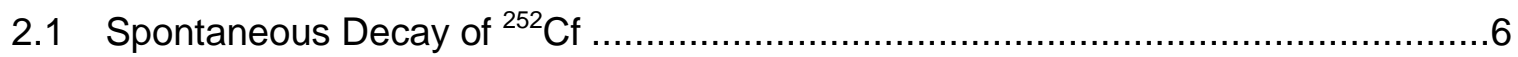

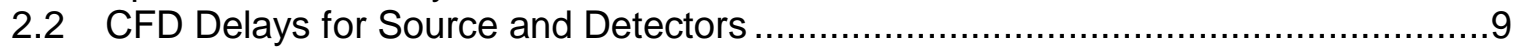

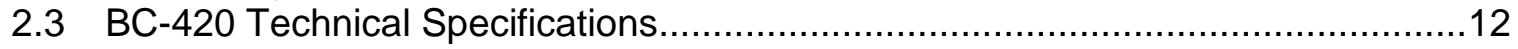

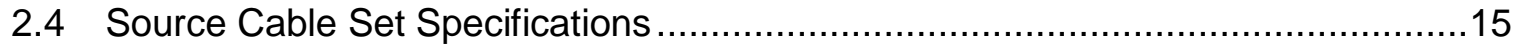

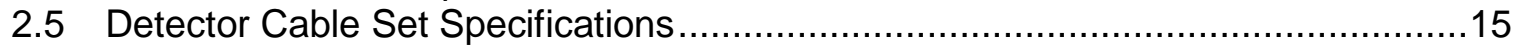

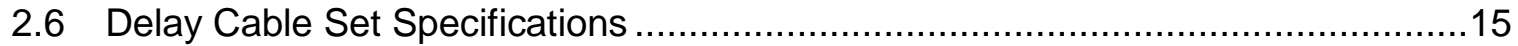

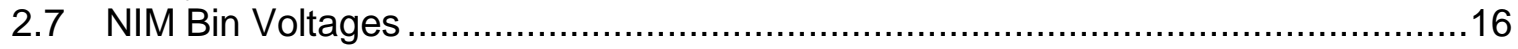

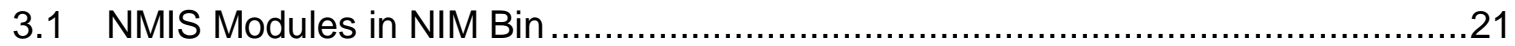

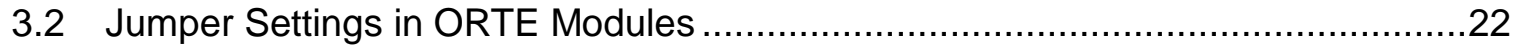

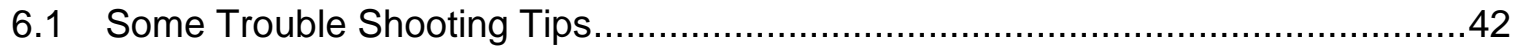

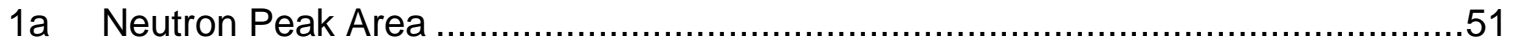

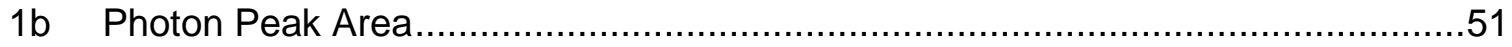

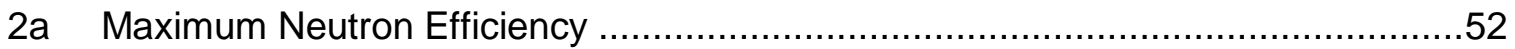

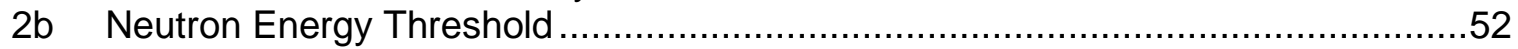




\section{LIST OF ACRONYMS}

$\begin{array}{ll}\text { APSD } & \text { Auto Power Spectral Density } \\ \text { ANWIS } & \text { Another Nuclear Weapons Identification System } \\ \text { CFD } & \text { Constant Fraction Discriminator } \\ \text { CPSD } & \text { Cross Power Spectral Density } \\ \text { DA } & \text { Data Acquisition } \\ \text { DAUI } & \text { Data Acquisition and User Interface } \\ \text { DC } & \text { Direct Current } \\ \text { DCC } & \text { Data Capture and Compression } \\ \text { FWHM } & \text { Full Width, Half Max } \\ \text { HV } & \text { High Voltage } \\ \text { IDAS } & \text { Interactive Data Analysis Software } \\ \text { ORNL } & \text { Oak Ridge National Laboratory } \\ \text { PCI } & \text { Peripheral Component Interconnect } \\ \text { PMT } & \text { Photomultiplier Tube } \\ \text { PS } & \text { Power Supply } \\ \text { NIM } & \text { Nuclear Instrument Module } \\ \text { NMIS } & \text { Nuclear Materials Identification System } \\ \text { NWIS } & \text { Nuclear Weapons Identification System } \\ \text { SHV } & \text { Safe High Voltage }\end{array}$




\section{ABSTRACT}

This report describes the operation and setup of the Nuclear Materials Identification System (NMIS) with a ${ }^{252} \mathrm{Cf}$ neutron source at the Oak Ridge Y-12 Plant. The components of the system are described with a description of the setup of the system along with an overview of the NMIS measurements for scanning, calibration, and confirmation of inventory items. 


\section{Chapter 1}

\section{INTRODUCTION}

The Nuclear Materials Identification System[26] (NMIS) was developed by the Oak Ridge National Laboratory and the Oak Ridge Y-12 National Security Complex at the Instrumentation and Controls Division for analyzing fissile and non-fissile materials. NMIS is a computer-based, high-speed time-dependent coincidence counting system that correlates up to five input channels. Fast plastic scintillating detectors are used to detect gamma and neutron radiations from the material being analyzed. The detector pulses are converted by hardware into binary pulse trains. Time-dependent coincidence distributions are then obtained by software from these pulse trains. The major components are a ${ }^{252} \mathrm{Cf}$ source embedded inside an ionization chamber, an amplifier, fast plastic organic scintillators and their associated photomultiplier tubes (PMT) and high voltage power supplies, constant fraction discriminators (CFD), delay module, and a custom dual-slot PCl board set (data capture and compression/data acquisition, DCC/DA) as shown in Figure 1.1 and referred to as the NMIS processor. The computer that houses the DA/DCC boards, used two programs to acquire and display the NMIS signatures. All the data acquisition is under the control of the Data Acquisition and User Interface (DAUI) program. All the data displays, data processing, and data plots are generated by the Interactive Data Analysis Software (IDAS) program.

Two NMIS operational modes are available for analyzing material, active and passive. As commonly used in the Safeguards community, active and passive refer to the source of radiations that are measured. In active mode, an external source is used to interrogate the object and it is this external source that induces fission and provides a majority of the radiations that are subsequently measured. On the other hand, there is no external stimulating source in passive measurements because the object itself is an inherent source of the radiations that are measured.

NMIS defines the term active slightly differently. In NMIS, active mode not only means that the source is external, but that it is also instrumented. Thus both source-detector and detector-detector time-dependent coincidence measurements are possible in active mode. Currently, the instrumented source is ${ }^{252} \mathrm{Cf}$ embedded in an ionization chamber, 1 which provides the primary source of gamma and neutron radiations via spontaneous fission. In passive mode, there is no external source since the material itself contains an inherent source of radiation, usually via spontaneous fission. Without an instrumented source, only detector-detector time-dependent coincidence distributions are possible in passive mode. Active mode is generally used to assay uranium and passive mode can be used to assay plutonium objects.

NMIS can compute three types of signatures from the input data streams: time domain, frequency domain, and multiplicities.2. Some of the time domain and frequency domain signatures are analogs of each other. For example, the Auto and Cross Power Spectral Densities are the frequency analogs of the Auto and Cross Correlation ${ }^{\text {function. }}$ Table 1.1 shows some of the most commonly used time and frequency domain signatures assuming that all five input channels are being used. The subscripts in the signature names

\footnotetext{
${ }^{1}$ Another alternative is a deuterium/tritium (DT) source coupled with an alpha detector.

${ }^{2}$ Traditionally, multiplicity strictly refers to neutron multiplicity. However, NMIS measures a joint gammaneutron multiplicity.

${ }^{3}$ Correlation function measures time-dependent coincidence distribution.
} 
refer to the input channel number. In active measurements, Channel 1 is the source and Channels 2 through 5 are the detectors. Thus for active mode, CROSS $_{12}$ is the cross correlation between the source and the first detector and $\mathrm{CROSS}_{23}$ is the cross correlation between the second and third detectors. In passive measurements, Channels 1 through 5 are detectors. Thus is passive mode, $\mathrm{CROSS}_{12}$ is the cross correlation between the first and second detector, and $\mathrm{CROSS}_{23}$ is the cross correlation between the second and third detectors.

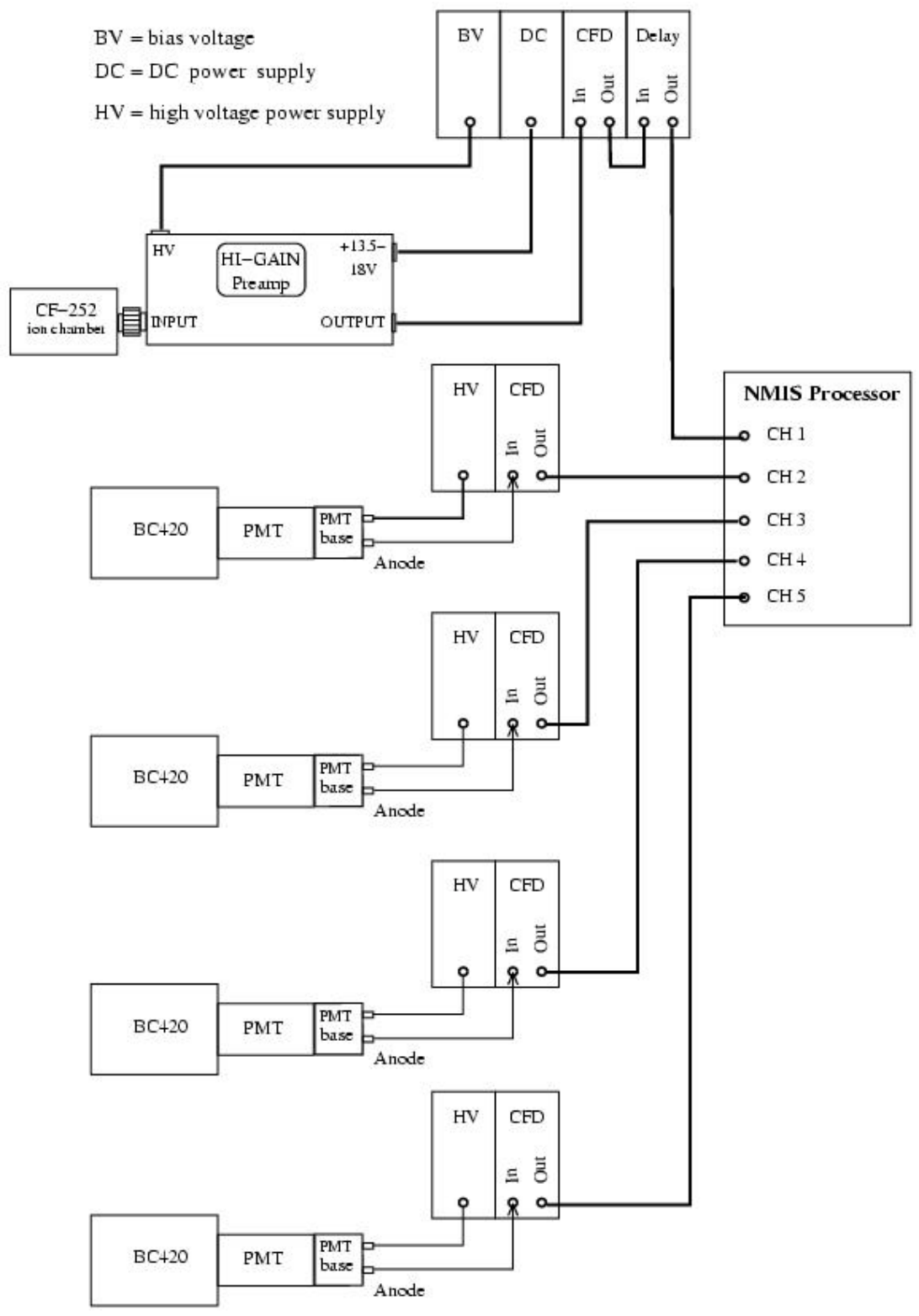

Figure 1.1. Block Diagram of Detection Systems for NMIS 
Table 1.1. Subset of NMIS Signatures for Five Input Channels

\begin{tabular}{|c|c|}
\hline \multicolumn{1}{|c|}{ Time Domain } & Frequency Domain $^{\text {b }}$ \\
\hline Autocorrelations & Auto Power Spectral Densities \\
\hline \hline AUTO $_{11}$ & APSD $_{11}$ \\
AUTO $_{22}$ & APSD $_{22}$ \\
AUTO $_{33}$ & APSD $_{33}$ \\
AUTO $_{44}$ & APSD $_{44}$ \\
AUTO $_{55}$ & APSD $_{55}$ \\
\hline Cross Correlations & Cross Power Spectral Densities $^{\text {a }}$ \\
\hline CROSS $_{12}$ & CPSD $_{12}(\mathrm{MG})$ \\
CROSS $_{13}$ & CPSD $_{13}(\mathrm{MG})$ \\
CROSS $_{14}$ & CPSD $_{14}(\mathrm{MG})$ \\
CROSS $_{15}$ & CPSD $_{15}(\mathrm{MG})$ \\
CROSS $_{23}$ & $\mathrm{CPSD}_{23}(\mathrm{MG})$ \\
CROSS $_{24}$ & $\mathrm{CPSD}_{24}(\mathrm{MG})$ \\
CROSS $_{25}$ & $\mathrm{CPSD}_{25}(\mathrm{MG})$ \\
CROSS $_{34}$ & $\mathrm{CPSD}_{34}(\mathrm{MG})$ \\
CROSS $_{35}$ & $\mathrm{CPSD}_{35}(\mathrm{MG})$ \\
CROSS $_{45}$ & $\mathrm{CPSD}_{45}(\mathrm{MG})$ \\
\hline
\end{tabular}

${ }^{a}$ Complex vector, i.e. real and imaginary parts: MG is the magnitude which is the square root of the sum of the squares of the real and imaginary parts.

becond column is just the Fourier transform of the first column. 


\section{Chapter 2}

\section{OVERVIEW OF COMPONENTS}

A complete NMIS consists of the following major hardware components:

- NMIS processor board set,

- NMIS processor power supply,

- Fast, plastic scintillation detectors in lead shields,

- Pulse processing electronics,

- Instrumented ${ }^{252} \mathrm{Cf}$ source, and

- Computer.

\subsection{NMIS PROCESSOR AND POWER SUPPLY}

The NMIS processor consists of 2 modular circuit boards, the Data Capture and Compression (DCC) board and the Data Acquisition (DA) board. These two boards are linked by on-board connectors and occupy two adjacent PCI slots. The DCC board accepts up to five channels of input data. In active mode, the first channel is reserved for the ${ }^{252} \mathrm{Cf}$ source and the remaining four channels may be used as detector inputs. ${ }^{4}$. $n$ passive mode, since there is no source, all five channels may be used as detector inputs. ${ }^{5}$ The DCC board expects the input data streams to be fast-NIM pulses which indicate the occurrence of detection events from the source and detector channels. In the source channel, a pulse indicates a ${ }^{252} \mathrm{Cf}$ fission 6 whereas a pulse in the detector channels indicates a gamma or neutron interaction in the detectors. The DCC board time tags each event pulse and compresses this data stream for the DA board. The DA board combines the five input data streams into a single stream and further compresses it so that it can be directly written to the computer's memory via the PCl bus. Rear view of the NMIS board set showing inputs as seen from the back is shown in Figure 2.1. Detectors are numbered 1 through 5 but the input channels are labeled $A-E$ in the software. The correspondence between detector numbers and input channels is shown in Figure 2.1 Detector 1 is the source channel in active measurements and is input $A$.

At present, the board set uses voltage levels and draws more power than the $\mathrm{PCl}$ bus-can supply so an external power supply must be used. The NMIS board power supply is equipped with sense lines to indicate whether the $+5 \mathrm{~V}$ from the computer is present (Figure 2.2). Therefore, if the computer is not powered up, the NMIS boards will not detect the proper sense line voltage and the NMIS power supply will not operate. (The new version of the processor boards does not need an additional power supply.)

\footnotetext{
${ }^{4}$ The software expects a minimum of three input channels: source and two detector inputs.

${ }^{5}$ The software expects a minimum of three input channels.

${ }^{6}$ For a DT source the pulse from the alpha detector is input to Channel 1.
} 


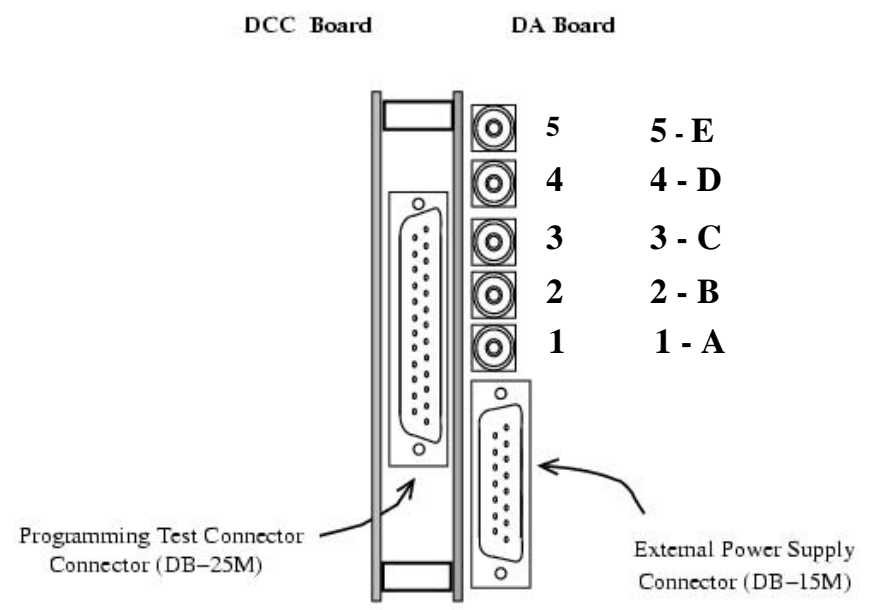

Figure 2.1. View of NMIS Board Set From Rear of Computer (Correspondence between the detector number and process channels indicated on the right.)

\subsection{CALIFORNIUM-252 SOURCE}

The source consists of a $1 \mathrm{~cm}$ diameter spot of ${ }^{252} \mathrm{Cf}$ plated onto the center of a circular platinum disk. The disk is then oriented inside an ionization chamber in a parallel plate configuration as shown in Figure 2.3. A hemispherical ionization chamber with improved performance is also used. The instrumented ${ }^{252} \mathrm{Cf}$ source is used to provide a trigger for NMIS whenever a source fission occurs. In order to detect when the fissions occur, a bias voltage is applied between the disk and the signal collecting electrode $1 \mathrm{~mm}$ away and parallel. The ionization chamber is typically filled with high purity $97 \% \mathrm{Ar}, 3 \% \mathrm{CO}_{2}$ gas mixture at $1 \mathrm{~atm}$ and operated in pulse-mode. Since the ionization chamber detects both the alpha decays and the spontaneous fissions from the ${ }^{252} \mathrm{Cf}$, the user must discriminate against the lower amplitude alpha pulses and electronic noise by properly setting the threshold voltage on the CFD. Some pertinent data on the spontaneous decay of ${ }^{252} \mathrm{Cf}$ are summarized in Table 2.1.

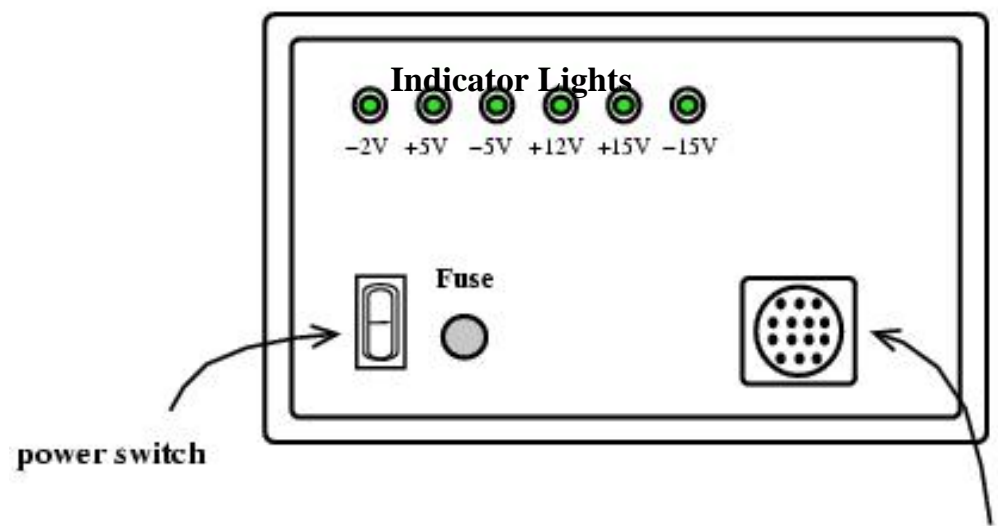

AMP cable connector

Figure 2.2. Front View of External Power Supply for NMIS Board Set 
Table 2.1. Spontaneous Decay of ${ }^{252} \mathrm{Cf}$

\begin{tabular}{|l|l|}
\hline Spontaneous fission specific activity & $6.14 \times 10^{5} / \mathrm{s} \cdot \mu \mathrm{g}$ \\
\hline Alpha-decay specific activity & $1.92 \times 10^{7} / \mathrm{s} \cdot \mu \mathrm{g}$ \\
\hline Energy of most probable light fission fragment & $\sim 105 \mathrm{MeV}$ \\
\hline Energy of most probable heavy fission fragment & $\sim 80 \mathrm{MeV}$ \\
\hline Average alpha energy & $6.11 \mathrm{MeV}$ \\
\hline Average energy of prompt neutron from spontaneous fission & $2.13 \mathrm{MeV}$ \\
\hline Average number of prompt neutrons from spontaneous fission & $3.77 / \mathrm{fission}$ \\
\hline
\end{tabular}

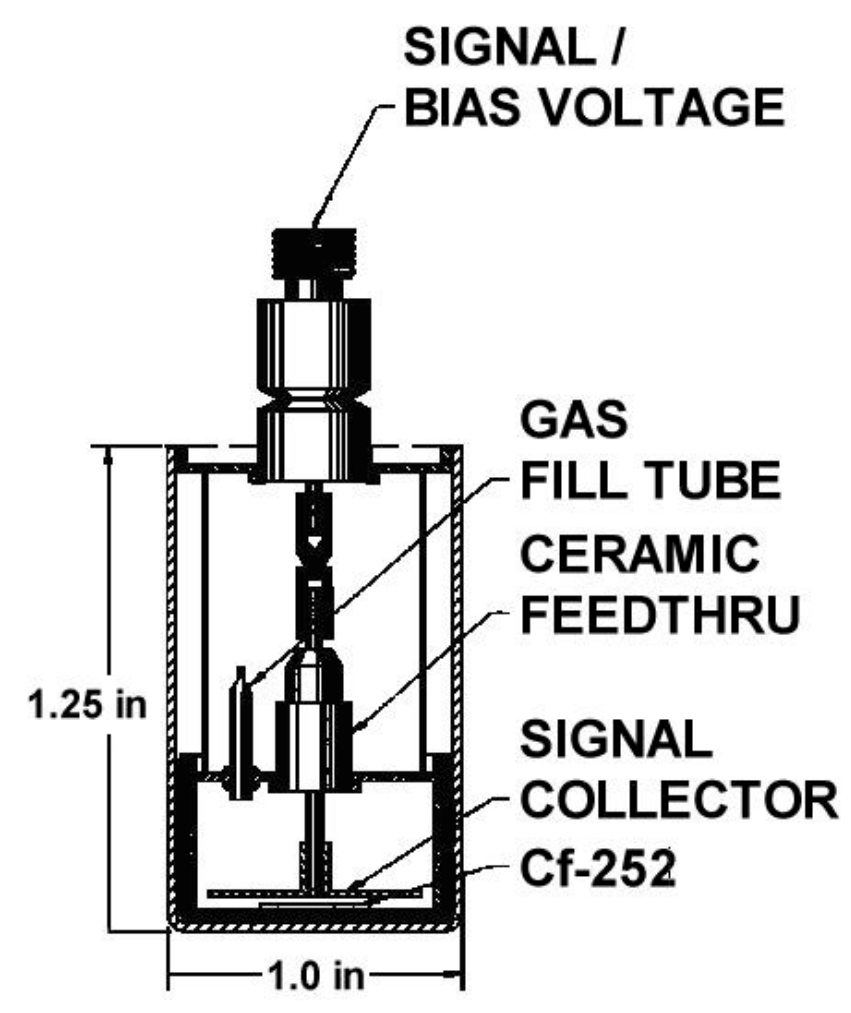

Figure 2.3. Schematic of ${ }^{252} \mathrm{Cf}$ Parallel Plate Ionization Chamber

The ionization chamber requires 200 VDC. The maximum rating $\theta_{\text {of }}$ the ionization chamber is 500 VDC.

Currently, due to the processing speed limitations of the CPU of the computer $(\approx 600$ $\mathrm{MHz}$ in 1999), NMIS is limited in real-time ${ }^{8}$ to a maximum source rate of approximately one million fissions per second which limits the source to around $1.5 \mu \mathrm{g}$ of ${ }^{252} \mathrm{Cf}$.

\footnotetext{
${ }^{7}$ Higher voltages may cause the chamber to spark between the electrodes and destroy the input electronics of the ${ }^{252} \mathrm{Cf}$ amplifier.

${ }^{8}$ Higher source rates force the NMIS data acquisition board into a slower, non-real-time mode to the initial processor boards.
} 


\subsection{IONIZATION CHAMBER AMPLIFIER}

The ORNL designed amplifier, Model Q-6456-1 is shown in Figure 2.4. This amplifier is a four-stage amplifier, with a total gain of $\sim 1800$ and rise time less than $1 \mathrm{nsec}$. The internal circuitry requires +15 VDC and is designed for $50 \Omega$ impedance input and output signals. There are four input/output connections. These connections and their purpose are summarized below:

- INPUT: BNC connector to attach ${ }^{252} \mathrm{Cf}$ ionization chamber,

- OUTPUT: amplified ionization chamber signal (goes to source channel CFD),

- +15 VDC: DC voltage for amplifier circuitry, and

- HV: 200 VDC bias voltage for the ${ }^{252} \mathrm{Cf}$ ionization chamber.

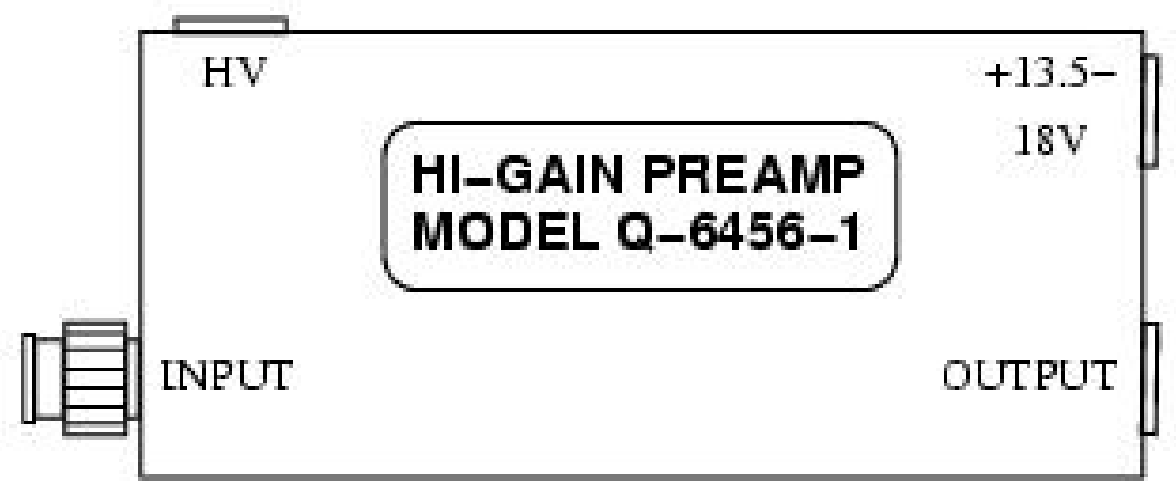

Figure 2.4. ORNL Designed Amplifier for ${ }^{252} \mathrm{Cf}$ Ionization Chamber

The +15 VDC and the +200 VDC bias voltages are supplied by the modules shown in Figure 2.5. This amplifier normally has $50 \mathrm{mV}$ noise pulses. If noise pulses are not present, the chamber is not working. If they are reduced in amplitude, then the amplifier has less gain. In both cases, the amplifier should replaced.

\subsection{CONSTANT FRACTION DISCRIMINATOR}

The purpose of the constant fraction discriminator (CFD) is to convert detector pulses of varying amplitude into a pulse-height independent, event-timing pulse. In other words, regardless of the pulse height, the CFD generates a timing pulse for NMIS to indicate when a detection pulse arrives. Typically, CFDs operate by setting a trigger point at some constant fraction of the rise-time of the pulse by converting the negative polarity detector pulse into a bipolar signal that a zero-crossing discriminator can use to generate a NIM-9 fast logic pulse. This design assumes that all the detector pulses have the same shape and only vary in their amplitudes.

\footnotetext{
${ }^{9}$ Nuclear Instrument Module
} 


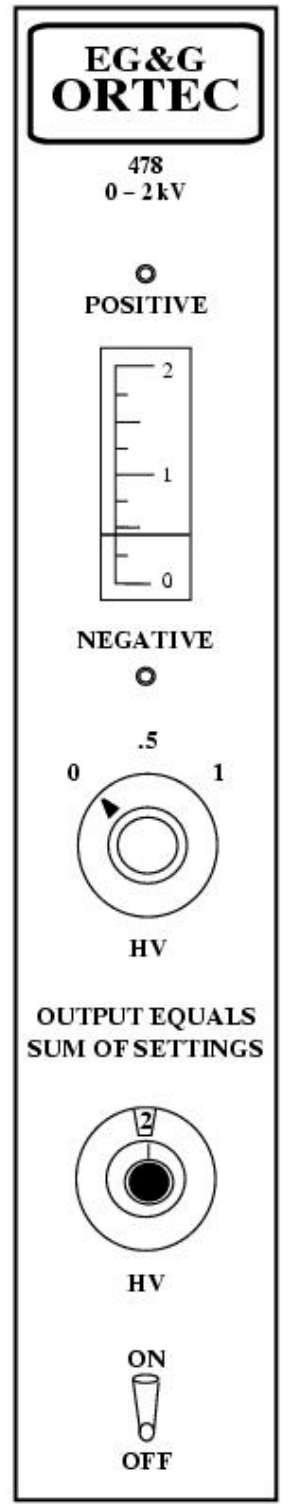

Source HV Bias

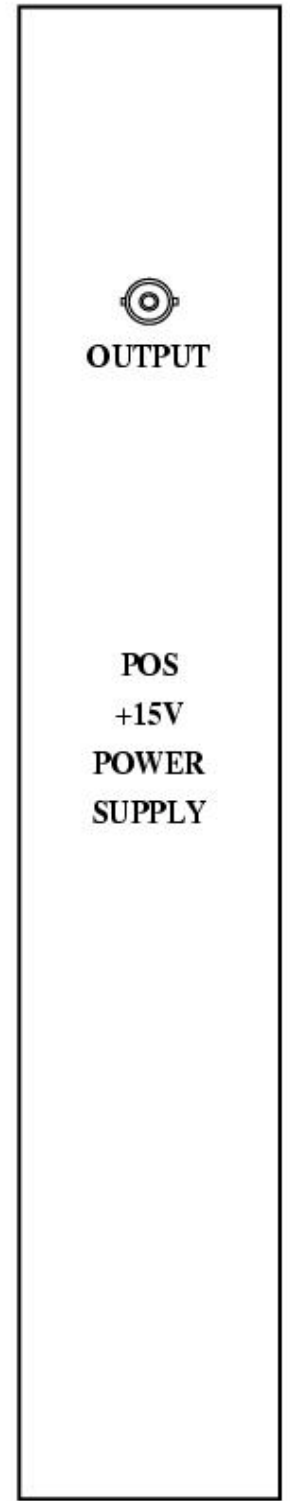

Amplifier DC Power Supply

Figure 2.5. HV Bias and DC Power Supply for Amplifier

The ORTEC 935 CFD converts a negative polarity detector pulse into a NIM fast logic pulse. The user typically sets the delay such that the CFD triggers at $20 \%$ of the rise-time. Due to the internal 1 nsec delay of the CFD circuitry itself, the length of the delay cable should be selected such that

$$
\tau_{\text {cable }}=\boldsymbol{t}_{20 \% \text { to full-amplitude }}+1 \boldsymbol{n} \text { sec } .
$$

Eight inches of cable corresponds to $1 \mathrm{nsec}$ of delay (for RG 58 and RG 174 cable). Typical delays are summarized below in Table 2.2. 
Table 2.2. CFD Delays for Source and Detectors

\begin{tabular}{|l|c|}
\hline \multicolumn{1}{|c|}{ Input } & Delay $(\mathrm{ns})$ \\
\hline${ }^{252} \mathrm{Cf}$ source & 2 \\
\hline $2 \times 2 \times 2$-inch detectors & 6 \\
\hline $2.75 \times 2.75 \times 4$-inch detectors & 6 \\
\hline $3.75 \times 3.75 \times 4$-inch detectors & 6 \\
\hline $6 \times 6 \times 4$-inch detectors & 4 \\
\hline
\end{tabular}

There are three other user settable controls on the CFD: threshold (T), walk (Z), and pulse width (W) as shown in Figure 2.6. The threshold is adjustable via a 20-turn potentiometer and the threshold test point varies from $-200 \mathrm{mV}$ to $-10 \mathrm{~V}$ which is a factor of 10 larger than the actual threshold voltage setting. This threshold setting depends on whether the input signal is from the ${ }^{252} \mathrm{Cf}$ ionization chamber or one of the detectors. To determine the threshold for the CFD source channel, a pulse height curve (such as shown in Figure 2.7) must be generated. The curve is generated by connecting the output of the ${ }^{252} \mathrm{Cf}$ source CFD to a counter and measuring the count rate for thresholds of $-35 \mathrm{mV}$ to $-120 \mathrm{mV}$ or test point readings from -350 to $1200 \mathrm{mV}$. A point at the midpoint of the counting plateau is usually selected as the threshold. The thresholds for the detector CFD's are usually set to $-40 \mathrm{mV}$ or a test point ready reading of $-400 \mathrm{mV}$.

The 20-turn walk potentiometer, which ranges from $\pm 15 \mathrm{mV}$, allows the user to finetune the voltage of the zero-crossing discriminator. The bipolar signal used by the zerocrossing discriminator is observable by running the monitor $(\mathrm{M})$ test point signal into Channel 1 and the output (Out) signal into Channel 2 of an oscilloscope and triggering off of Channel 2. The optimum setting is when all the bipolar pulses cross the baseline at the same point.

The pulse width is adjustable by a 20-turn potentiometer. Generally, a pulse width of $10 \mathrm{~ns}$ to $40 \mathrm{~ns}$ has been used with 20 ns being a near optimal setting. The pulse width will determine, to a large extent, the dead time of NMIS so narrower pulses should be used if possible. Conditions such as ringing in the source or detector PMT bases may force the use of pulse widths larger than $20 \mathrm{~ns} .10$ Pulse widths wider than 20 ns may indicate a malfunction of the PMT bases or detector signal cables.

The CFD can be operated in either of two modes: blocking or updating. In blocking mode, if a second pulse arrives within a time period equal to the output pulse width, W, after the first pulse, the second pulse will be ignored, or blocked from affecting the output from the fist pulse. In this case, the pulse width is simply, W. If however, the CFD is in updating mode, the width of the output pulse will be equal to the difference in arrival times of the first and second pulse, plus the normal output width.

\section{NOTE}

The CFD is normally shipped from the factory in updating mode. NMIS operation requires blocking mode so jumper W2 on the CFD circuit board must be set to enable blocking mode.

\footnotetext{
${ }^{10}$ This is obvious by examining the measured auto correlation function of each detector channel.
} 


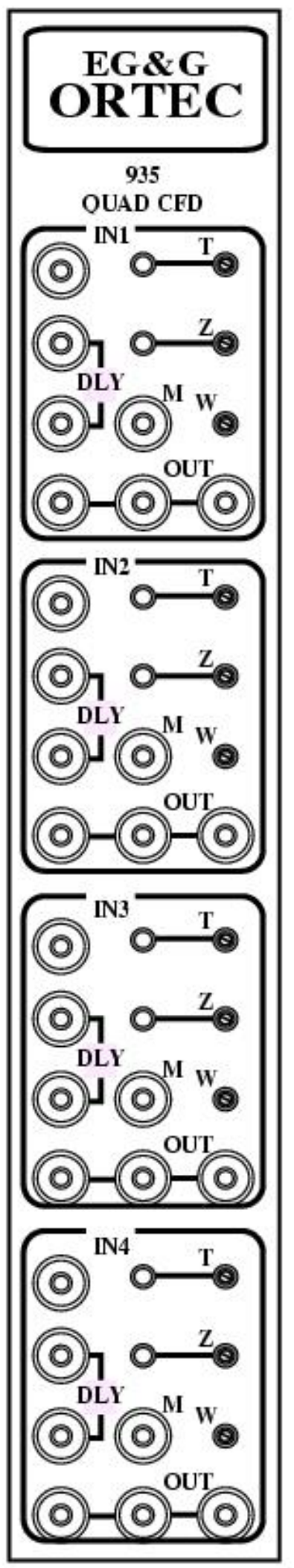

Figure 2.6. ORTEC Quad Constant Fraction Discriminator 


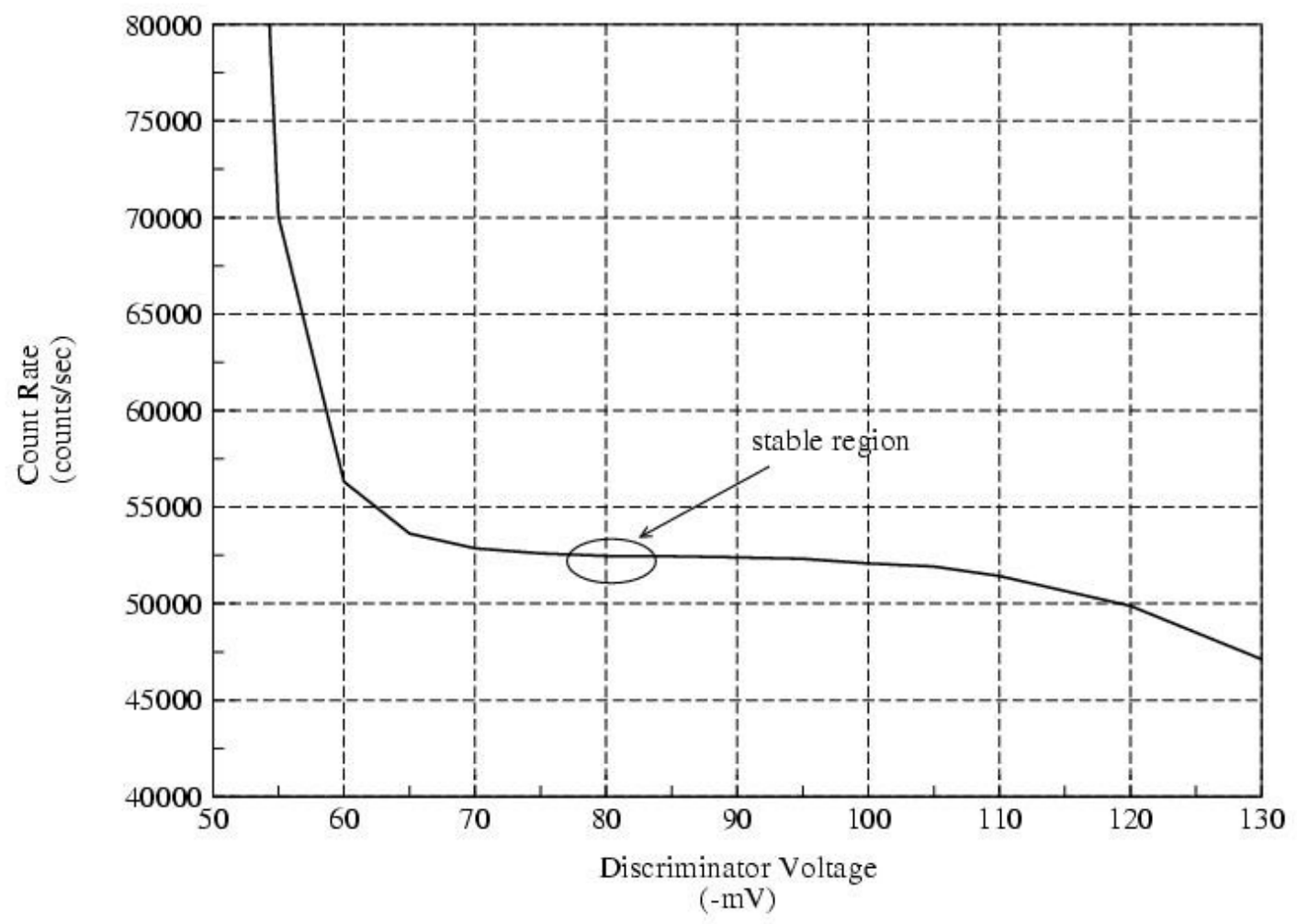

Figure 2.7. Pulse Height Curve for Q-6456 Amplifier for ${ }^{252} \mathrm{Cf}$ Source Ionization Chamber Output

\subsection{DETECTORS AND ASSOCIATED ELECTRONICS}

The detectors presently used in NMIS are sensitive to both gamma rays and neutrons. They consist of plastic scintillators coupled with photomultiplier tubes (PMT) and customized Philips voltage dividers (PMT base). The scintillating material, a solid organic, is manufactured by Bicron and is intended for fast timing or counting applications. Some of the technical data is summarized in Table 2.3. Although the PMTs can be operated with either positive or negative voltages, all the NMIS PMTs are operated with positive voltages. Thus, all the PMT bases thatare shipped with the detectors must be modified in-house to operate with positive voltages. ${ }^{11}$ Likewise, the ORTEC 556 detector power supplies can source either positive or negative voltages. To select positive voltage on this power supply, turn the polarity selector screw on the rear of the power supply to the positive position as shown in Figure 2.8. Since the power supplies are not being remotely controlled, the Control toggle switch on the rear should be set to the INT position. Finally, for standard operation, the power selection switch should be set to $115 \mathrm{~V}$.

\footnotetext{
${ }^{11}$ This modification is documented in ORNL Drawing Q6612-4
} 
Table 2.3. BC-420 Technical Specifications

\begin{tabular}{|l|l|}
\hline \multicolumn{1}{|c|}{ Material } & \multicolumn{1}{|c|}{ Polyvinyl Toluene } \\
\hline Density & $1.032 \mathrm{~g} / \mathrm{cm}^{3}$ \\
\hline Atomic Ratio, H/C & $\sim 1.1$ \\
\hline Atomic Number Density of Hydrogen & $5.21 \times 10^{22} / \mathrm{cm}^{3}$ \\
\hline Atomic Number Density of Carbon & $4.74 \times 10^{22} / \mathrm{cm}^{3}$ \\
\hline Electron Density & $3.37 \times 10^{23} / \mathrm{cm}^{3}$ \\
\hline Light Output, Percent of Anthracene & 64 \\
\hline Rise Time & $0.5 \mathrm{~ns}$ \\
\hline Decay Time & $1.5 \mathrm{~ns}$ \\
\hline Pulse Width at FWHM & $1.3 \mathrm{~ns}$ \\
\hline 1/e light attenuation length & $140 \mathrm{~cm}$ \\
\hline maximum wavelength of emission & $391 \mathrm{~nm}$ \\
\hline
\end{tabular}

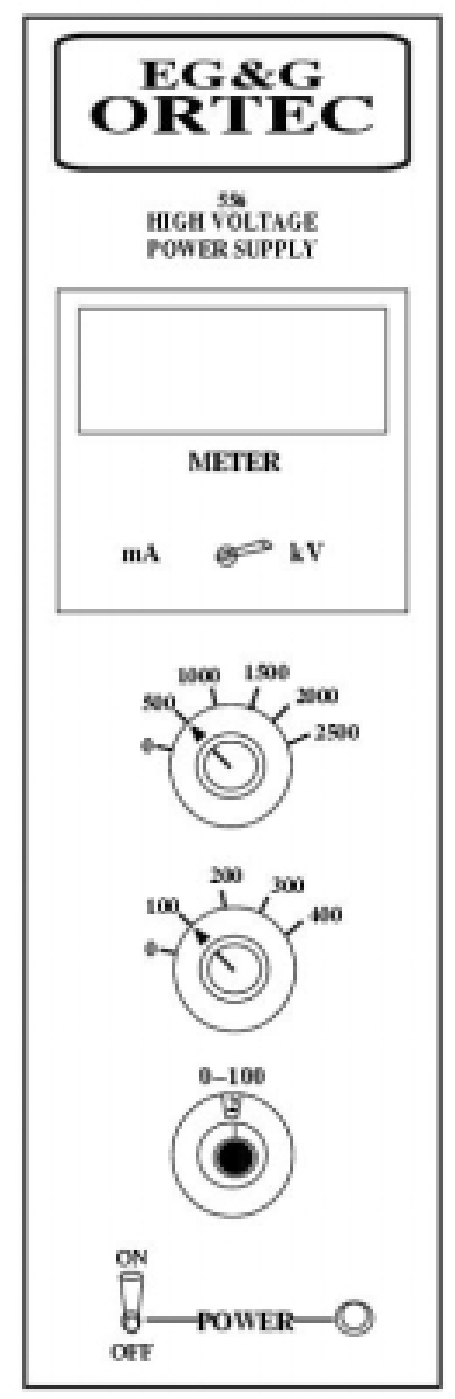

FRONT

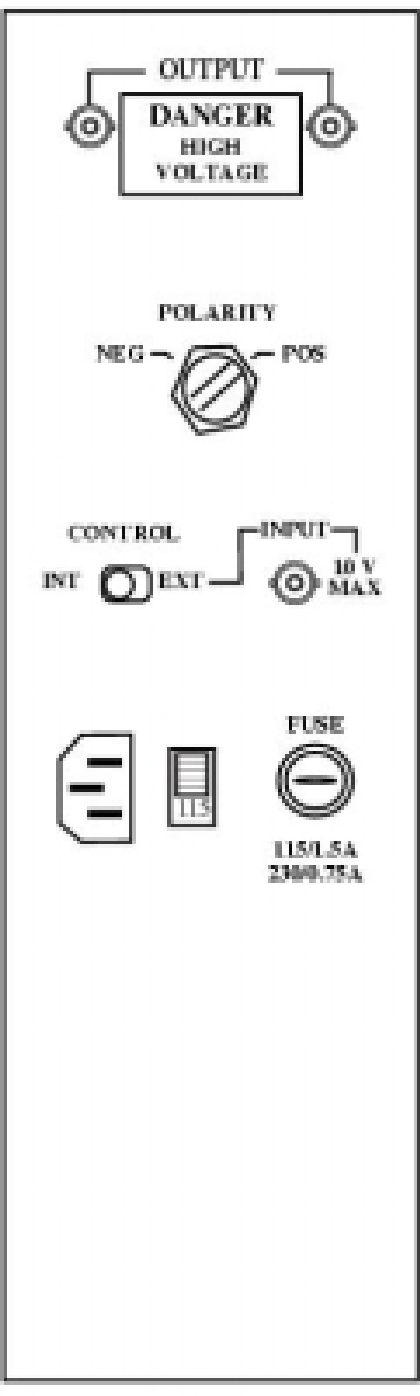

BACK

Figure 2.8. High Voltage Power Supply for NMIS Detectors 


\subsection{DELAY MODULE}

The delay module, as shown in Figure 2.9 is a NIM module that can provide from 1 ns to 63 ns of delay in 1 ns steps. This module is used to provide the appropriate amount of delay in the source channel to compensate for differences in signal propagation time through the source and detector channels. Even if the source and detector cables have the same length, the signal propagation times differ because the ionization chamber signal generates an output signal much faster than the detector PMTs. The delay is correct when the gamma peak in the time of flight spectrum appears in the time bin corresponding to the source-detector distance. (Photons travel at the speed of light so for a source-detector spacing of 1 meter, the gamma peak should appear at 3.3 nanoseconds.)

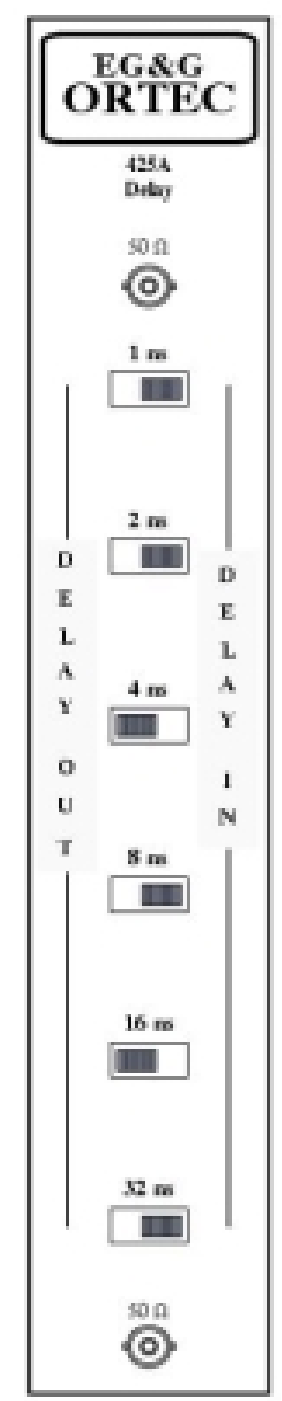

Figure 2.9. ORTEC Delay Module 
Since the signal cables for the source and detectors typically vary from 25 to 50 feet in length, delays greater than 75 ns are not required. The EG\&G ORTEC Model 425A Nanosecond Delay provides a total of 63 ns of delay in 1-ns steps. The delays are implemented by cascading RG-58A/U coaxial cables that are interconnected. The $425 \mathrm{~A}$ Delay Module does not require power to operate.

\subsection{COUNTER}

The counter is primarily used to measure the count rate of the source. During normal operation, it can be simply used to monitor the source channel. During the initial setup of the NMIS instrumentation it is used to generate the pulse height curve. The ORTEC Quad counter/timer, Model 974 has three counter inputs as shown in Figure 2.10 although only one channel can be displayed at any time.

\section{NOTE}

The ORTEC 974 Counter/timer is normally shipped from the factory to count positive pulses. NMIS generates negative pulses.

Refer to the ORTEC manual on how to switch the counter to count negative pulses. Make sure that all four channels inside the counter are converted!

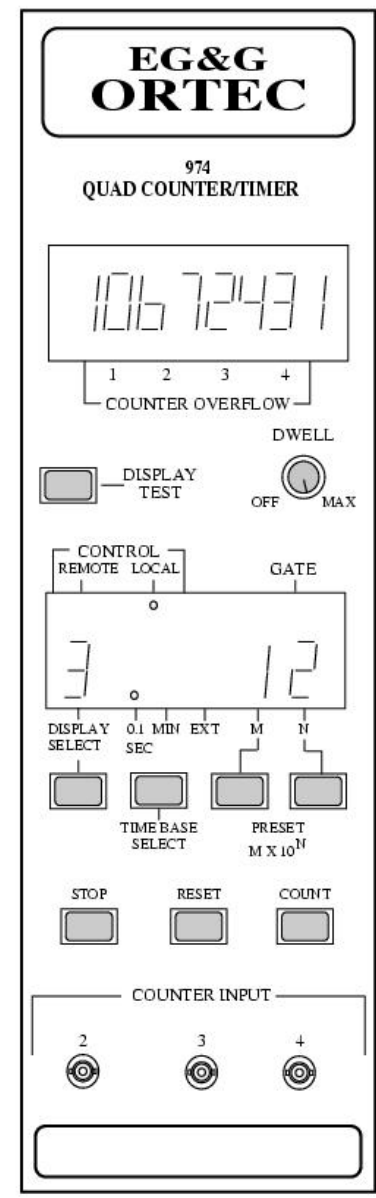

Figure 2.10. ORTEC Quad Counter/Timer, Model 974. 


\section{$2.8 \quad$ CABLES}

Three types of cables are used in NMIS: signal cables, power cables (both high and low voltage), and delay cables. Each cable type has a specific type of connector. The signal cables use BNC connectors, the HV cables use SHV connectors, and the delay cables use LEMO-style connectors. Some basic cable information for the source, detector, and delay cable sets are summarized in Tables 2.4, 2.5, and 2.6.

Table 2.4. Source Cable Set Specifications

\begin{tabular}{|c|c|c|c|c|c|}
\hline Quantity & Length & Cable Type & Connectors & Label & Function \\
\hline \hline 1 & $50 \mathrm{ft}$. & RG58 & BNC/BNC & Signal & signal (fission) \\
1 & $50 \mathrm{ft}$. & RG59 & BNC/SHV & HV & bias \\
1 & $50 \mathrm{ft}$. & RG58 & BNC/BNC & $+15 \mathrm{VDC}$ & amplifier power \\
\hline
\end{tabular}

Table 2.5. Detector Cable Set Specifications

\begin{tabular}{|c|c|c|c|c|c|}
\hline Quantity & Length & Cable Type & Connectors & Label & Function \\
\hline \hline 1 & $50 \mathrm{ft.}$ & RG58 & BNC/BNC & A & signal \\
1 & $50 \mathrm{ft.}$ & RG59 & SHV/SHV & A & HV supply \\
\hline 1 & $50 \mathrm{ft.}$ & RG58 & BNC/BNC & B & signal \\
1 & $50 \mathrm{ft.}$ & RG59 & SHV/SHV & B & HV supply \\
\hline 1 & $50 \mathrm{ft.}$ & RG58 & BNC/BNC & C & signal \\
1 & $50 \mathrm{ft.}$ & RG59 & SHV/SHV & C & HV supply \\
\hline 1 & $50 \mathrm{ft.}$ & RG58 & BNC/BNC & D & signal \\
1 & $50 \mathrm{ft.}$ & RG59 & SHV/SHV & D & HV supply \\
\hline
\end{tabular}

Table 2.6. Delay Cable Set Specifications

\begin{tabular}{|c|c|c|c|c|}
\hline Quantity & Length & Cable Type & Connectors & Label \\
\hline 4 & 64 in. & RG174 & LEMO/LEMO & $8 \mathrm{~ns}$ \\
\hline 4 & 48 in. & RG174 & LEMO/LEMO & $6 \mathrm{~ns}$ \\
\hline 4 & 32 in. & RG174 & LEMO/LEMO & $4 \mathrm{~ns}$ \\
\hline 4 & 24 in. & RG174 & LEMO/LEMO & $3 \mathrm{~ns}$ \\
\hline 4 & 16 in. & RG174 & LEMO/LEMO & $2 \mathrm{~ns}$ \\
\hline 4 & 8 in. & RG174 & LEMO/LEMO & $1 \mathrm{~ns}$ \\
\hline 4 & 4 in. & RG174 & LEMO/LEMO & $.5 \mathrm{~ns}$ \\
\hline 4 & 2 in. & RG174 & LEMO/LEMO & $.25 \mathrm{~ns}$ \\
\hline
\end{tabular}


All signal (RG58) and delay cables (RG174) must have a nominal impedance of $50 \Omega$ to prevent impedance mismatch and signal reflections. Signal propagation time in both the signal and delay cables is roughly 1 nanosecond per 8 inches of cable.

\subsection{NIM BIN}

NMIS uses a 19-inch rack compatible. NIM bin capable of housing up to twelve single-slot modules. Some of the NMIS modules are double width. NMIS can use any NIM bin as long as the bin power supply can source the voltages at the indicated rating in Table 2.7. Note that some NIM bins do not provide \pm 6 VDC since this voltage was not required by the original NIM standard. 12 NMIS however, used the ORTEC 935 CFD that does require this voltage. 13

\section{Table 2.7. NIM Bin Voltages}

\begin{tabular}{|c|c|}
\hline Voltage & Minimum Rating \\
\hline +6 VDC & $10 \mathrm{~A}$ \\
\hline$-6 \mathrm{VDC}$ & $10 \mathrm{~A}$ \\
\hline$+12 \mathrm{VDC}$ & $3 \mathrm{~A}$ \\
\hline$-12 \mathrm{VDC}$ & $3 \mathrm{~A}$ \\
\hline$+24 \mathrm{VDC}$ & $1.5 \mathrm{~A}$ \\
\hline$-24 \mathrm{VDC}$ & $1.5 \mathrm{~A}$ \\
\hline
\end{tabular}

With the exception of the high voltage power supplies for the detectors (ORTEC 564), all the other NIM modules rely on the NIM bin for power. Since the detector power supplies do not rely on the NIM bin, these modules can be located outside the NIM bin.

\subsection{LEAD SHIELD}

The detectors are usually encased on five sides (face and four sides) by $1 / 4$-inch of lead shielding. The lead shield holds either two or four detectors in a linear array. Standalone measurements use the four-detector stack whereas in-place measurements in the storage arrays use the two-detector stack. These are illustrated in Figures 2.11 and 2.12. The detectors have been color coded from bottom to top: red, blue, green, and yellow correspond to detectors $2,3,4$, and 5 respectively. The blue detector is aligned opposite the source.

\footnotetext{
${ }^{12}$ Even if the NIM bin has front panel test points for \pm 6 VDC, the rear power supply may not provide this voltage.

${ }^{13}$ Any NIM modules containing integrated circuits, such as the ORTEC 935 CFD, will require \pm 6 VDC.
} 


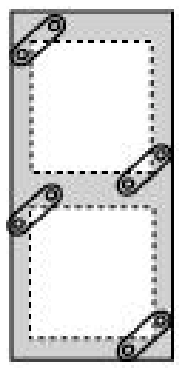

(teat)
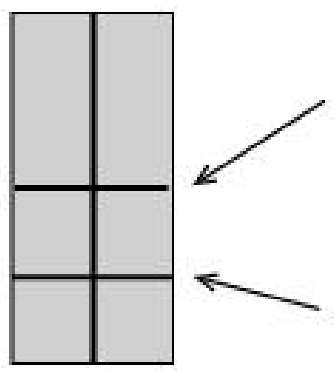

centetline of detector stack (TOF measurement)

centetline of blue detector (standard measurements)

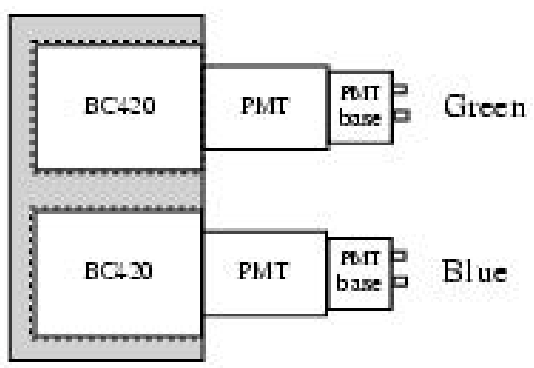

(side)

(fiont)

Figure 2.11. Two-Detector Stack in Lead Shield.

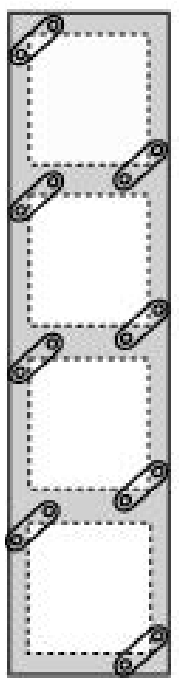

(teat)
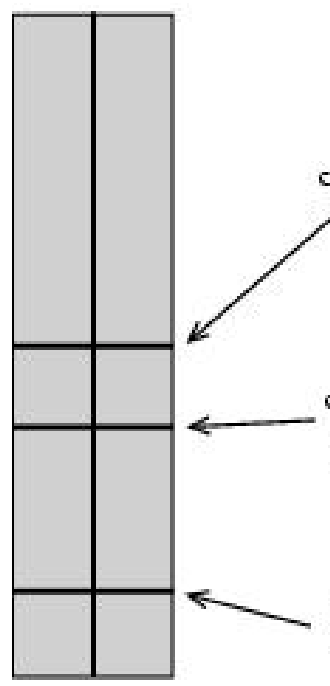

centerline of detector stack (TOF measutement)

centetline of blue detector (standard measurements) centerline of ted detector (scanning meas utements)

(fiont)

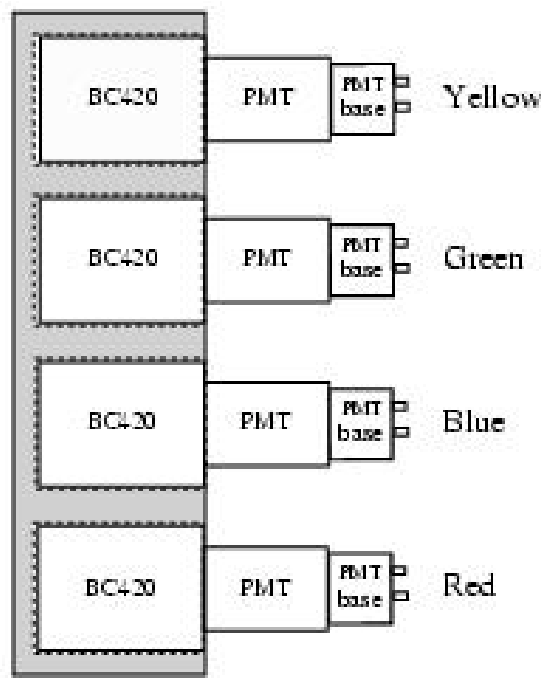

(side)

Figure 2.12. Four-Detector Stack in Lead Shield. 


\section{Chapter 3}

\section{INITIAL SETUP}

This section describes the procedure on how to assemble the NMIS equipment. The following test equipment is required.

- Oscilloscope (350 MHz or faster),

- Small screw driver to adjust potentiometers,

- $\quad$ Digital multimeter, and

- Assorted delay cables (0.25 to 8 ns).

All electronic equipment described in this section operates on $120 \mathrm{VAC}, 60 \mathrm{~Hz}$ power but can be made to operate at other voltages and frequencies through the use of converters and power conditioners. The use of power converters and filtering devices are not covered in this document.

The general installation procedure consists of the following steps.

1. Install the NMIS processor in the host computer.

2. Install the software.

3. Install instrumentation modules in the NIM bin and cart.

4. Connect the source $\left({ }^{252} \mathrm{Cf}\right.$ embedded in an ionization chamber) to the amplifier. Before this connection, short the chamber with a $50 \Omega$ connector to remove any charge buildup on the collecting electrode of the chamber.

5. Connect the detectors.

6. Conduct a time-of-flight measurement and finish adjusting the detector high voltage and delays.

\subsection{INSTALLATION OF NMIS PROCESSOR} fan.

The NMIS processor boards (Ga As) requires an external power supply and a cooling

1. Turn off all power to the computer.

2. Remove the cover on the computer so that the PCI slots are accessible. You will need three adjacent PCl slots, two for the board, and one for the fan.

3. Install the double-slot NMIS processor.

4. Install the cooling fan so that it draws air away from the large heat sink on the NMIS board. 
5. Reinstall the computer cover.

6. Connect the NMIS board external power supply to the NMIS board.

7. Turn on the NMIS board external power supply.

8. Turn on the computer. Verify that all the front panel LEDs on the external power supply are on (green on Figure 2.2).

9. See Section 3.2.1 for instructions to install the NT driver for the board.

\subsection{SOFTWARE INSTALLATION}

There are four major parts of the software that must be installed for NMIS. These programs can be found on the NMIS distribution CD-ROM.

- da.sys and instdrv.exe: the board driver for the NMIS data acquisition board and the NT driver installation program,

- gpent-rt: the graphics library,

- DAUI: NMIS data acquisition software, and

- IDAS: NMIS post data capture display software.

In order to install the above software under Windows NT, Administrator privileges are required so log into the Administrator account or an account with full administrator privileges.

\subsubsection{Installation of NT Board Driver}

Follow these steps to install the NT driver for the NMIS board.

1. Verify that the NMIS processor is installed and that it is connected to the external power supply.

2. Verify that the NMIS processor's external power supply is turned on and that all the front panel LEDs are lit.

3. Make a folder names NMIS under C:IProgram Files.

4. Copy the driver installation file instdrv.exe to C:IProgram FilesINMIS.

5. Copy the driver da.sys to C:IProgram FilesINMIS. If you can't see the driver file, then the file manager is hiding system files. To correct this situation, select the following: View, Options, View tab, click on "Show all files."

6. Open a DOS window and type the following to install the driver:

(a) cd C:IProgram Files $\backslash$ NMIS

(b) instdrv da0 C:|Program Files|NMISIda.sys 
7. Activate the driver so that NT loads it at boot up:

(a) Open the Control Panel.

(b) Open the Driver module (double click on driver icon).

(c) Set the da0 driver to automatically start on boot up.

\subsubsection{Installation of Graphics Library}

Follow these steps to install the graphics library used by IDAS.

1. Copy the folder gpcnt-rt to C:IProgram Files\NMIS.

2. Define the GPCWIN environment variable as follows:

(a) Open the Control Panel.

(b) Open the System module.

(c) Go to the Environment screen (click on Environment tab).

(d) In variable window, type the name of the environment variable, "GPCWIN."

(e) In the settings window type the path where the graphics library was installed, "C:IProgram Files\NMISIgpcnt-rt."

(f) Click on "Apply."

(g) Click on "OK."

\subsubsection{Installation of DAUI and IDAS}

1. Make a folder whose name corresponds to the version number of DAUI and IDAS in C:IProgram FilesiNMIS. For example, if the version is 0.9 .2 , you could name the folder ver0.9.2.

2. Copy the DAUI and IDAS (ANWIS) executable files, daui.exe and anwis.exe into this folder.

3. In the folder C:IProgram Files\NMIS, copy the versions of the DAUI and IDAS programs that you currently are using.

4. On the Desktop or Startup Menu, create shortcuts, i.e. links, to the DAUI and IDAS programs in C:IProgram Files\NMIS.

5. To optimize DAUI performance, NMIS users should be granted the following privileges (see Administrative Tools/User Manager/Policies/User Rights):

(a) Increase quotas, 
(b) Increase scheduling priority, and

(c) Lock pages in memory.

\subsection{NMIS CART}

The NMIS cart, with the exception of the detectors and source/amplifier, holds all of the electronics and the computer. The cart has three levels. The computer monitor, keyboard, and mouse are all on the topmost level for easy access. On the middle shelf are the NIM bin and detector power supplies. Finally, on the bottom shelf are the NMIS board power supply, computer, external Jazz drive, and power strips.

The modules listed in Table 3.1 must be inserted into the NIM bin for proper operation. A typical NIM bin configuration is shown in Figure 3.1. Since the detector power supplies run directly off of 120 VAC line power, they do not have to be in the NIM bin. If space permits though, these modules may be inserted into the NIM bin.

Table 3.1. NMIS Modules in NIM Bin

\begin{tabular}{|c|c|c|}
\hline Module & Model & Quantity \\
\hline CFD & ORTEC 935 & 2 \\
\hline Delay & ORTEC 425A & 1 \\
\hline +15V Preamp & -- & 1 \\
\hline Ion Chamber PS & ORTEC 478 & 1 \\
\hline Counter & ORTEC 974 & 1 \\
\hline
\end{tabular}

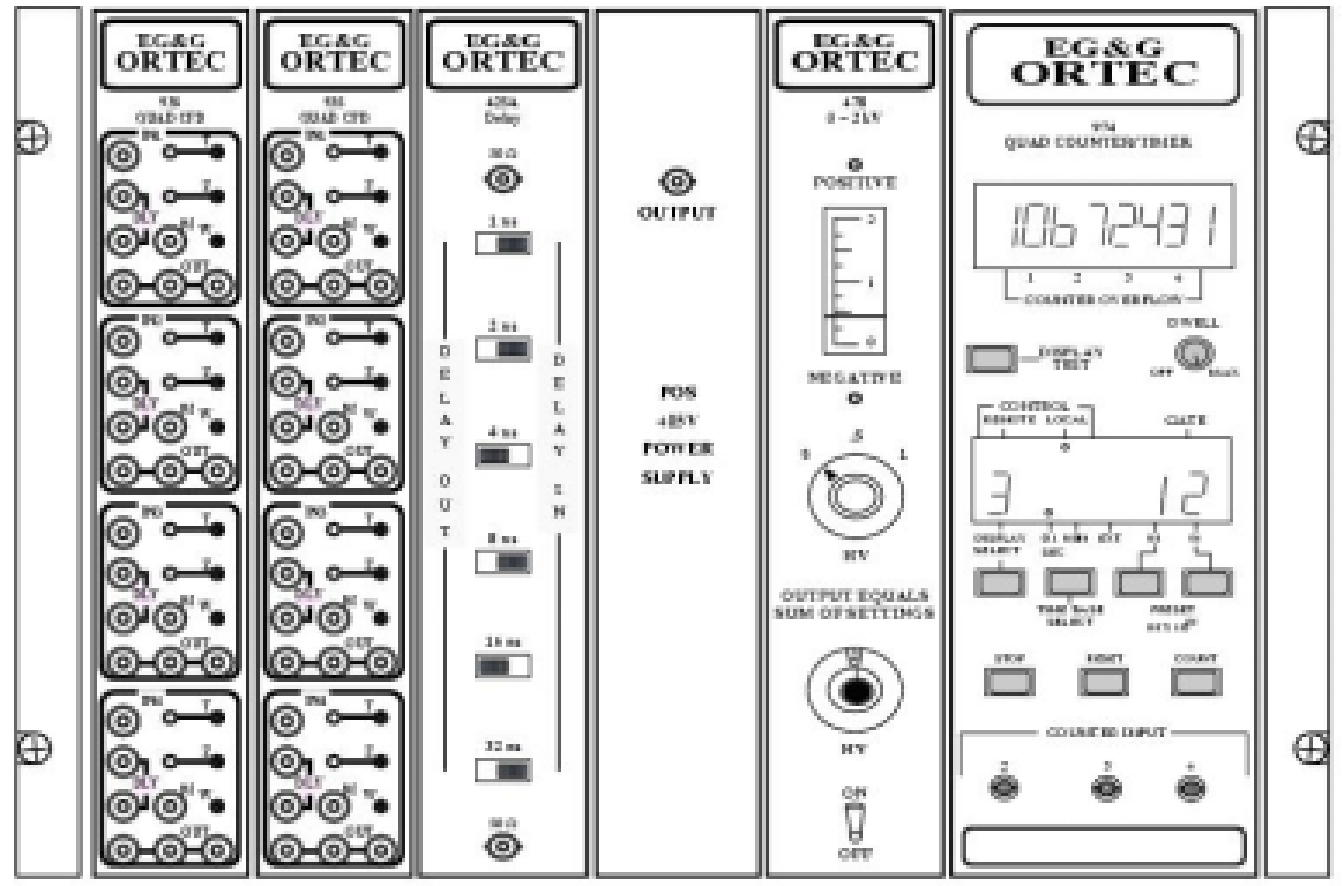

Figure 3.1. NIM Bin Configuration Without Scintillation Power Supplies (Voltage for source power supply show at 400 volts rather than the normal operating voltage of 200V). 
For proper operation, verify the following jumper settings by removing the side plate of the modules listed in Table 3.2.

Table 3.2. Jumper Settings in ORTEC Modules

\begin{tabular}{|c|c|c|c|}
\hline Module & Model & Jumper & Setting \\
\hline CFD & ORTEC 935 & $\begin{array}{c}\text { Updating/Blocking (W2) } \\
\text { Internal Delay (W1) }\end{array}$ & $\begin{array}{c}\text { Blocking } \\
\text { Removed }\end{array}$ \\
\hline Counter & ORTEC 974 & Polarity & Negative \\
\hline
\end{tabular}

\section{$3.4{ }^{252} \mathrm{CF}$ SOURCE SETUP}

WARNING!

Turn off power to the NIM bin before connecting +15 or +200 VDC to the amplifier. Do not turn power on until after the ionization chamber has been connected to the amplifier. Failure to do so will cause permanent damage to the amplifier necessitating its replacement.

1. Set the ion chamber power supply to zero volts and turn on the power supply to verify it is set to positive polarity. This module is usually shipped with the polarity set to positive voltage. If the negative polarity LED is lit, turn off the power supply and switch it to positive polarity. (The module must be internally switched. Refer to ORTEC manual.)

2. Turn off the ionization chamber power supply. Turn off power to the NIM bin.

3. Connect the ion chamber to the amplifier.

4. Connect the amplifier as shown in Figure 3.2.

5. Turn on power to the NIM bin. Adjust the ionization chamber power supply to +200 VDC.

6. See Section 4.1.1 to determine the proper length of the delay cable to the CFD. (In general, the delay cable should be approximately 2 ns for the source.)

7. Set the zero crossing point using the Zero potentiometer. (See Section 4.1.3 for details.)

8. Set the output pulse width of the CFD. (See Section 4.1.4 for details.)

9. Generate a pulse height curve to determine the discriminator threshold and set it. (See Section 4.1.2 for details.) 


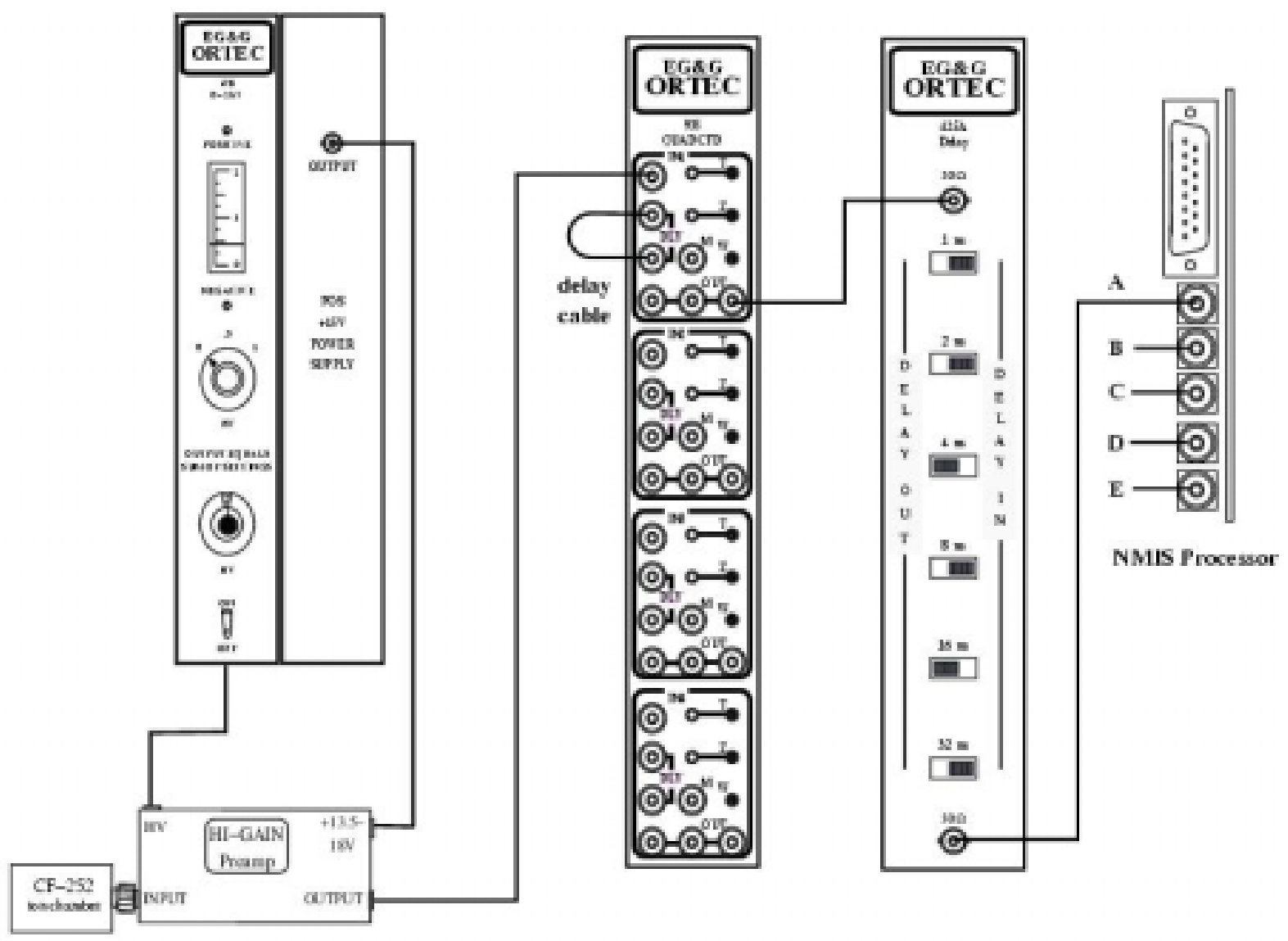

Figure 3.2. ${ }^{252} \mathrm{Cf}$ Source Connections for Either Receipts or Inventory Measurements (NMIS Processor Input Inverted for Convenience of Sketch.)

\subsection{DETECTOR SETUP}

Either a two-detector or four-detector setup is used depending on the measurement. Standalone measurements use the four-detector setup whereas in-place measurements (in the storage arrays) use two-detector setups. Currently, all receipts measurements use the four-detector setup and most inventory measurements use the two-detector setup.

\subsubsection{Four-Detector Setup}

1. Turn off power to the detector power supplies. Verify that the polarity switches are on the rear of the high voltage power supplies are set to the POS (positive) setting. On the front of the detector power supplies, set the toggle switches for the LCD readout to the $\mathbf{k V}$ position.

2. Place the four detectors in the lead shield assembly in either a horizontal or vertical array. For the majority of measurements, the vertical array is used. See classified attachment for receipt item requiring horizontal detector array. 
3. Connect the detectors as shown in Figure 3.3. The HV cables are terminated in SHV connectors. The detector signal cable is terminated on both ends with BNC connectors. Use a BNC-to-LEMO adapter to attach the end of the signal cable to the CFDs.

4. Set the high voltage to the detectors in steps to 1500 VDC pausing slightly after each step.

5. See Section 4.1.1 to determine the proper length of the delay cable. (In general, the delay cable should be approximately 6 ns for the 4 -inch detectors.)

6. Set the discriminator threshold to $-40 \mathrm{mV}(-400 \mathrm{mV}$ on the multimeter). (See Section 4.1.2 for details.)

7. Set the zero crossing point using the Zero potentiometer. (See Section 4.1.3 for details.)

8. Set the output pulse width of the CFD such that it is equal to or wider than the input pulse width. (See Section 4.1.4 for details.)

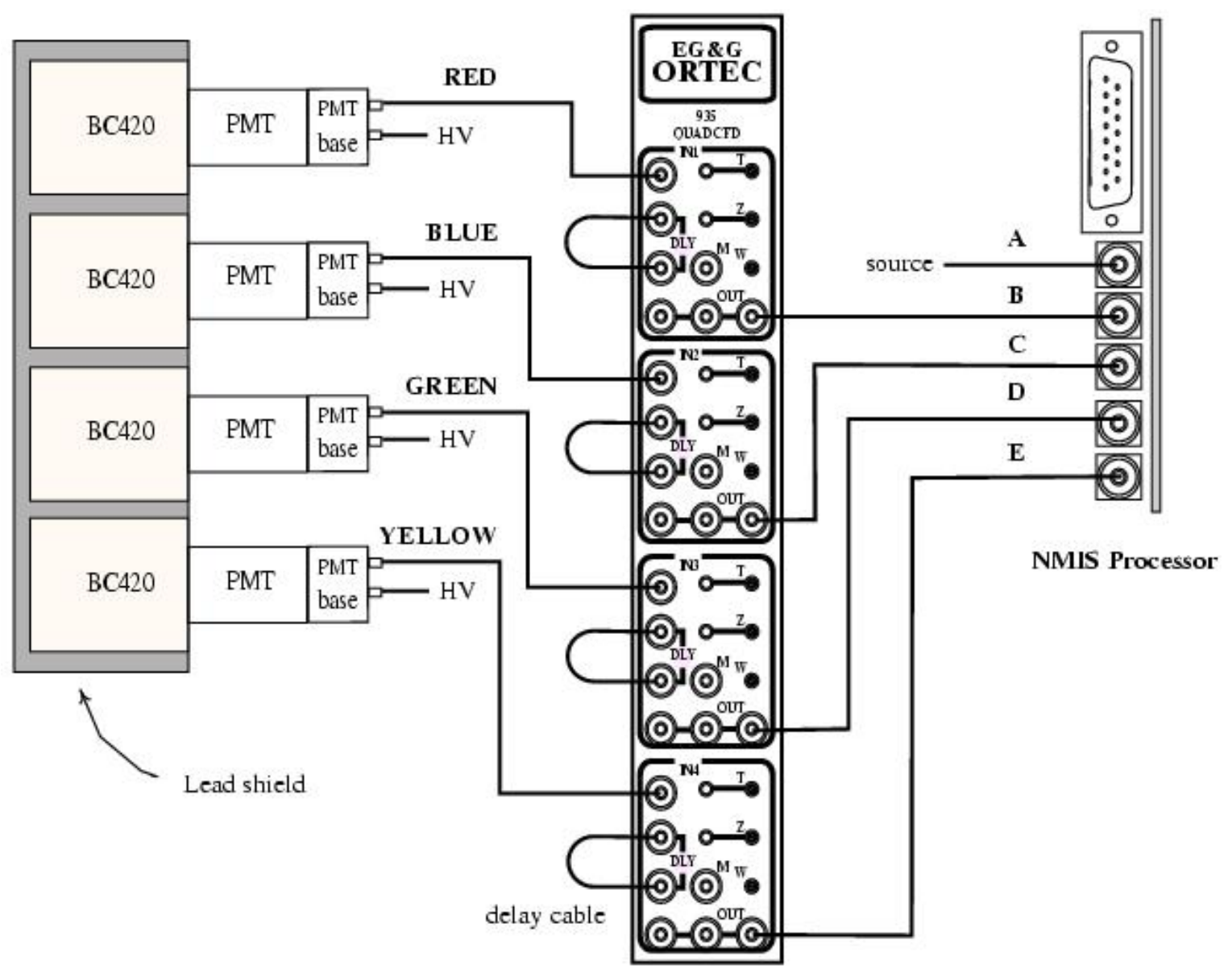

Figure 3.3. Detector Connections for all Receipt Measurements (Detectors and NMIS Processor Inputs inverted from the way they are located to simplify the sketch.) 


\subsubsection{Two-Detector Setup}

1. Turn off power to the detector power supplies. Verify that the polarity switches located on the rear of the high voltage power supplies are set to the POS (positive) setting. Set the toggle switches for the LCD readout on the front of the detector power supplies to the $\mathbf{k V}$ position.

2. Place the two detectors in the lead shield assembly in a vertical array.

3. Connect the detectors as shown in Figure 3.4 or Figure 3.5. The HV cables are terminated with SHV connectors. The detector signal cable is terminated on both ends with BNC connectors. Use a BNC-to-LEMO adapter to attach the end of the signal cable to the CFDs.

4. Set the high voltage for the detectors in steps to 1500 VDC pausing slightly after each step.

5. See Section 4.1.1 to determine the proper length of the delay cable. (In general, the delay cable should be approximately 6 ns for the 4-inch detectors.

6. Set the discriminator threshold to $-40 \mathrm{mV}$ (-400 mV on the multimeter). (See Section 4.1.2 for details.)

7. Set the zero crossing point using the Zero potentiometer. (See Section 4.1.3 for details.)

8. Set the output pulse width of the CFD such that it is equal to or wider than the input pulse. (See Section 4.1.4 for details.)

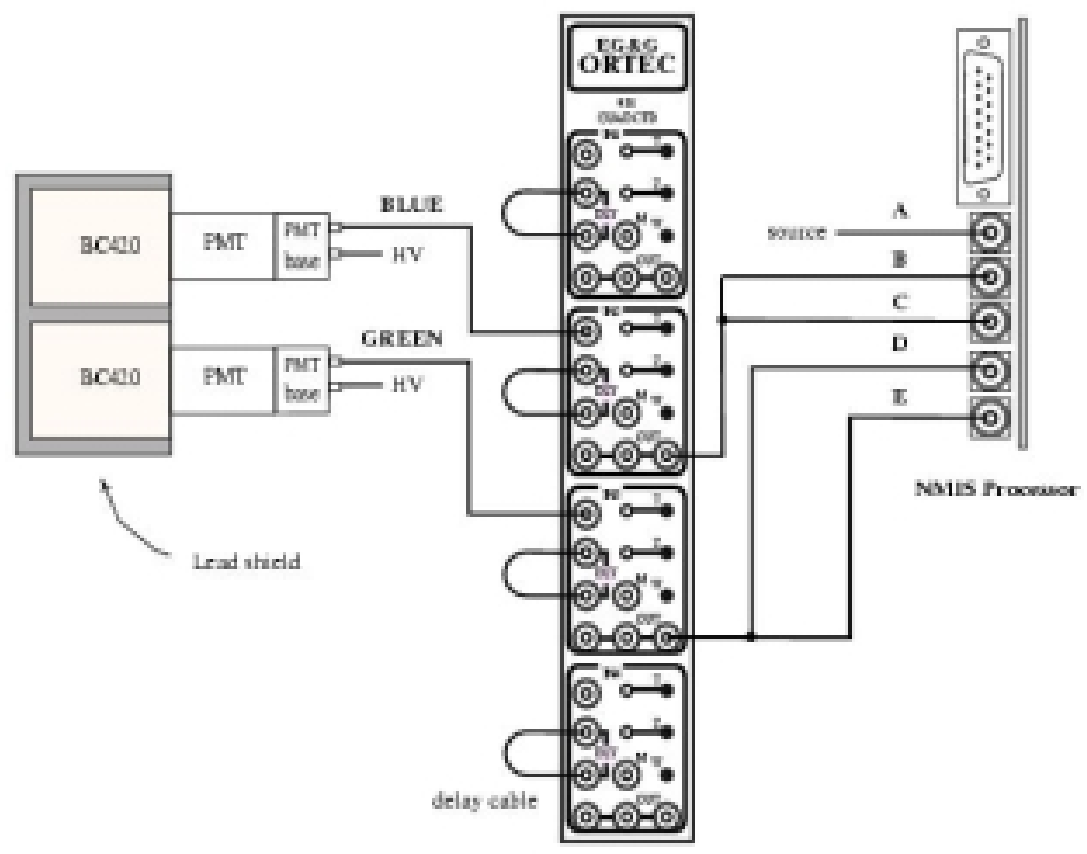

Figure 3.4. Two-Detector Connections for Temporary Two-Detector Setup (NMIS Processor Inputs Shown Inverted for Convenience of Sketch.) 


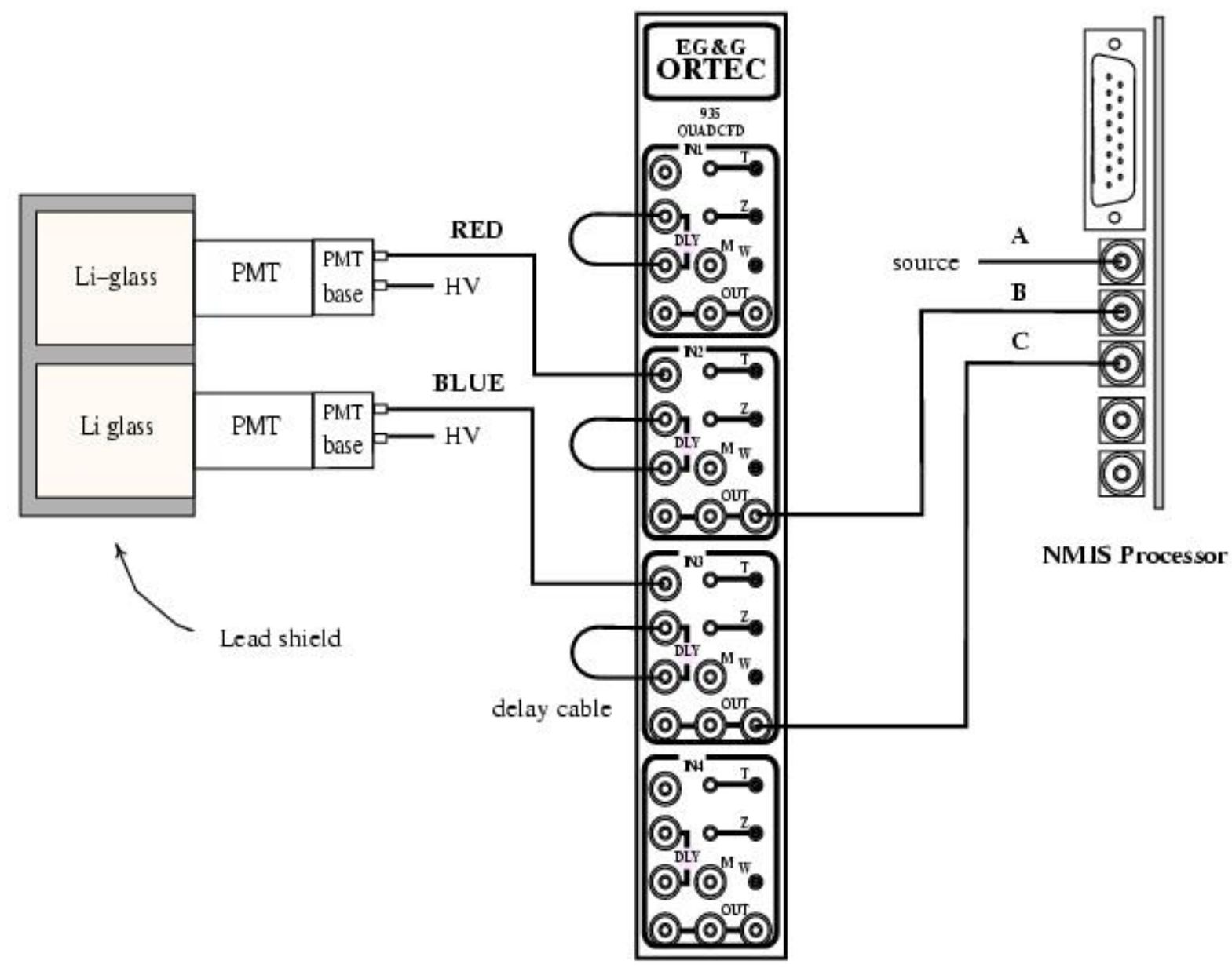

Figure 3.5. Two-Detector Connections for Two-Detector Setup (NMIS Processor Inputs Shown Inverted for Convenience of Sketch.)

\subsection{DETECTOR NEUTRON RESPONSE}

The final step is to align all the detectors so that they all have the same neutron response. This is accomplished by performing a time-of-flight (TOF) measurement using DAUI and then using IDAS to compute the peak neutron efficiencies and neutron threshold energy. For more detailed instructions, see Section 4.2. These steps should be performed after the detectors and the NMIS electronics have had sufficient time to warm up and stabilize, usually half day or more for the power supply voltages for the scintillators.

1. Setup the source and detectors as shown in Figure 3.6. Try to place the detectors and source at least 2 meters from large reflecting and scattering objects such as walls, people, or fissile material.

(a) Raise the horizontal midline of the detector stack and the source until both are 36 inches off the floor. 
(b) Horizontally separate the detector stack and the source such that their faces are 40 inches apart.

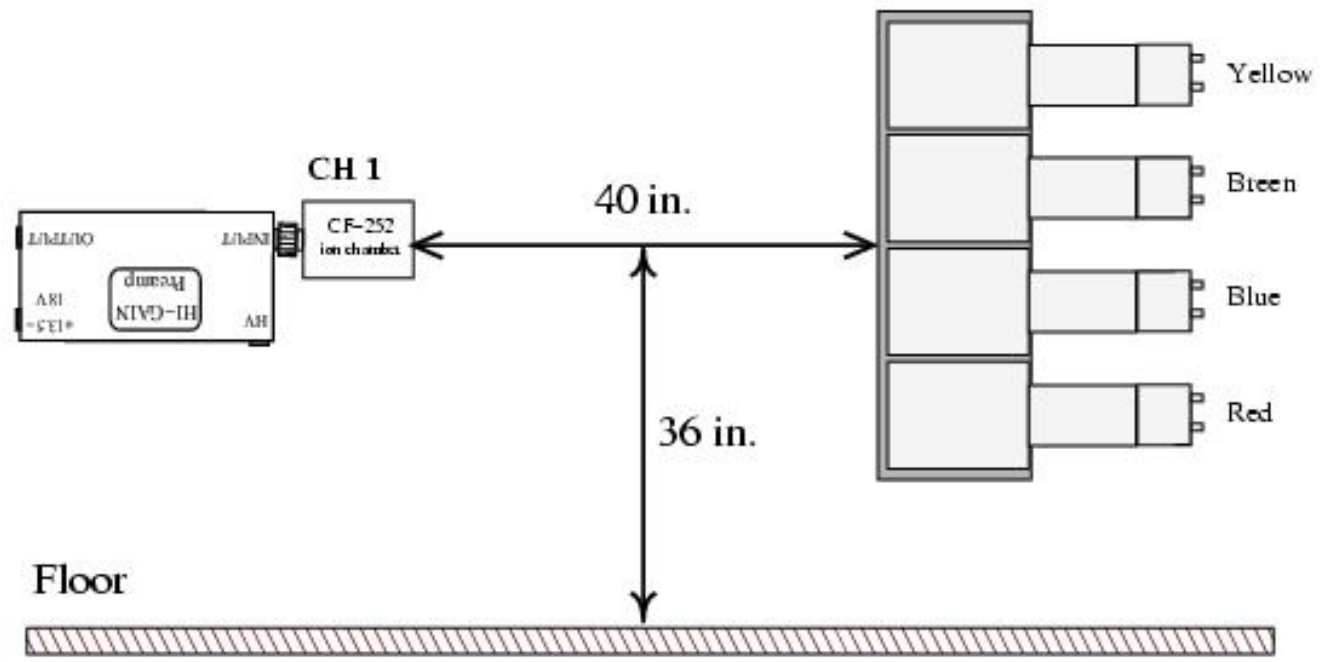

Figure 3.6. Time-of-Flight Setup to Determine Detector Efficiencies

2. Acquire Time-of-Flight (TOF) data using DAUI. A typical result of a TOF is shown in Figure 3.7. (See Section 4.2.)

3. Verify that the location of the gamma peak is $3.3 \pm 0.1$ nanosecond using IDAS. (See Section 4.2.1.) ( $10^{7}$ blocks are all that is needed for this.)

- If the peak occurs too soon, lengthen the CFD output signal cable for each detector.

- If the peak occurs too late, shorten the CFD output signal cable for each detector.

- If all the peaks are off in the same direction, change the delay in the source channel (addition delay to the source channel moves the peaks to the left whereas removing delay from the source channel moves the peaks to the right).

4. Compute detector efficiencies using IDAS. (See Section 4.3.)

5. Verify that all peak efficiencies are $63 \pm 1$ percent. A typical detector efficiency curve is shown in Figure 3.8. (See Section 4.2.2.)

- If peak efficiencies are too low, increase HV to PMT base of the detector.

- If peak efficiencies are too high, decrease HV to PMT base of the detector.

- Rule of Thumb: $10 \mathrm{mV}$ change in HV corresponds to 1 percent change in efficiency.

6. Repeat above procedures until the gamma peaks appear between 3.2 to 3.4 nanoseconds and all detector peak efficiencies are between 62 and 64 percent. Usually, if the detectors are warmed up, the detector efficiencies will only change by $1 \%$ or less.

Detection efficiencies obtained for the two central (blue and green) may be different with the top (red) and bottom (yellow) removed. Since there is some scattering of particles from the red detectors into the blue detectors that would not be there in a detection efficiency determination with only the two central detectors. As a result, reference template and detection efficiencies obtained with four detectors may not correspond to those using two 
detectors only. In addition, presence of structural material adjacent to the sides of the detectors scatters neutrons into the detectors that would normally pass by and not be detected and presence of such materials should be avoided.

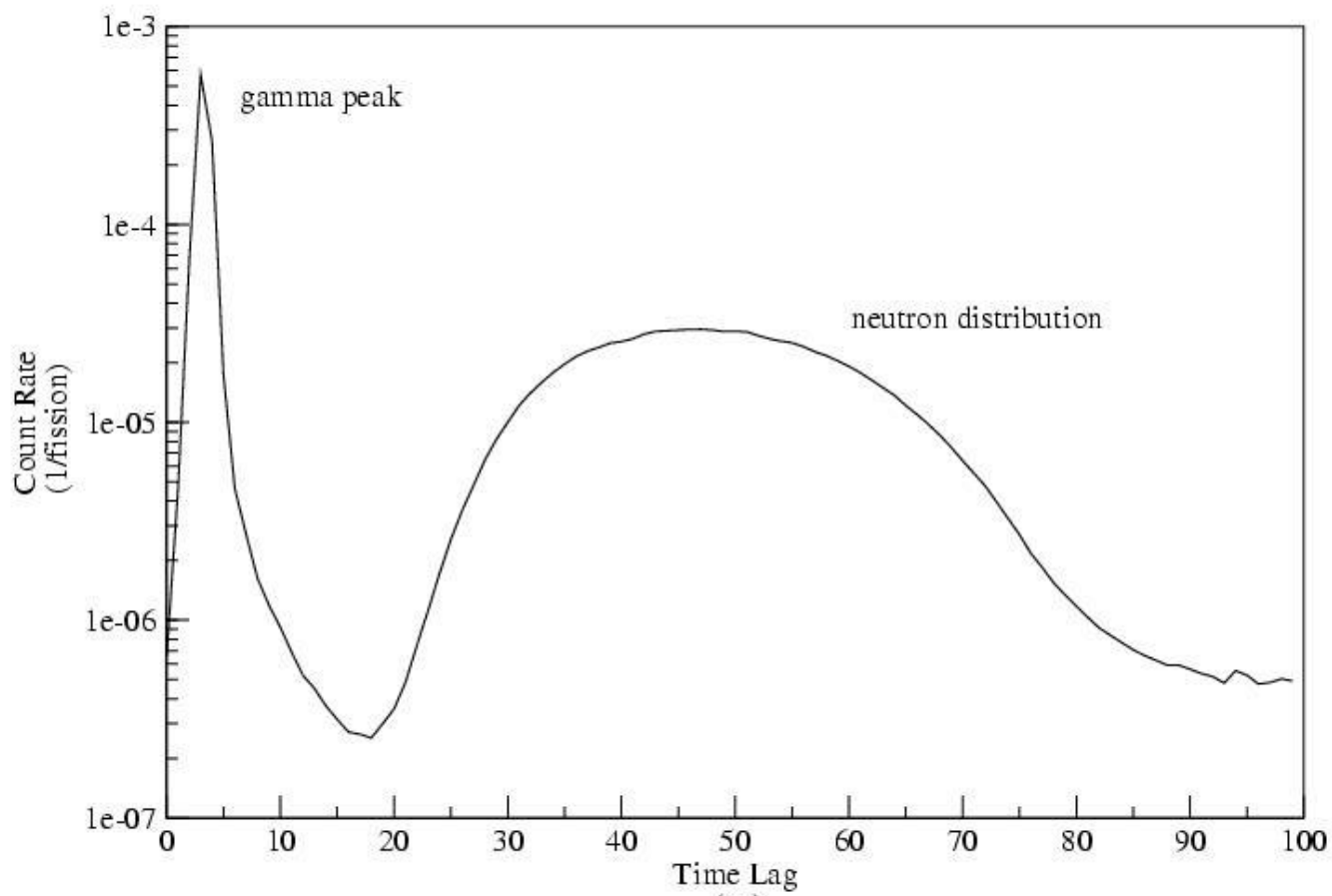

(ns)

Figure 3.7. Time of Flight for Source/Detector Spacing $=1 \mathrm{~m}$

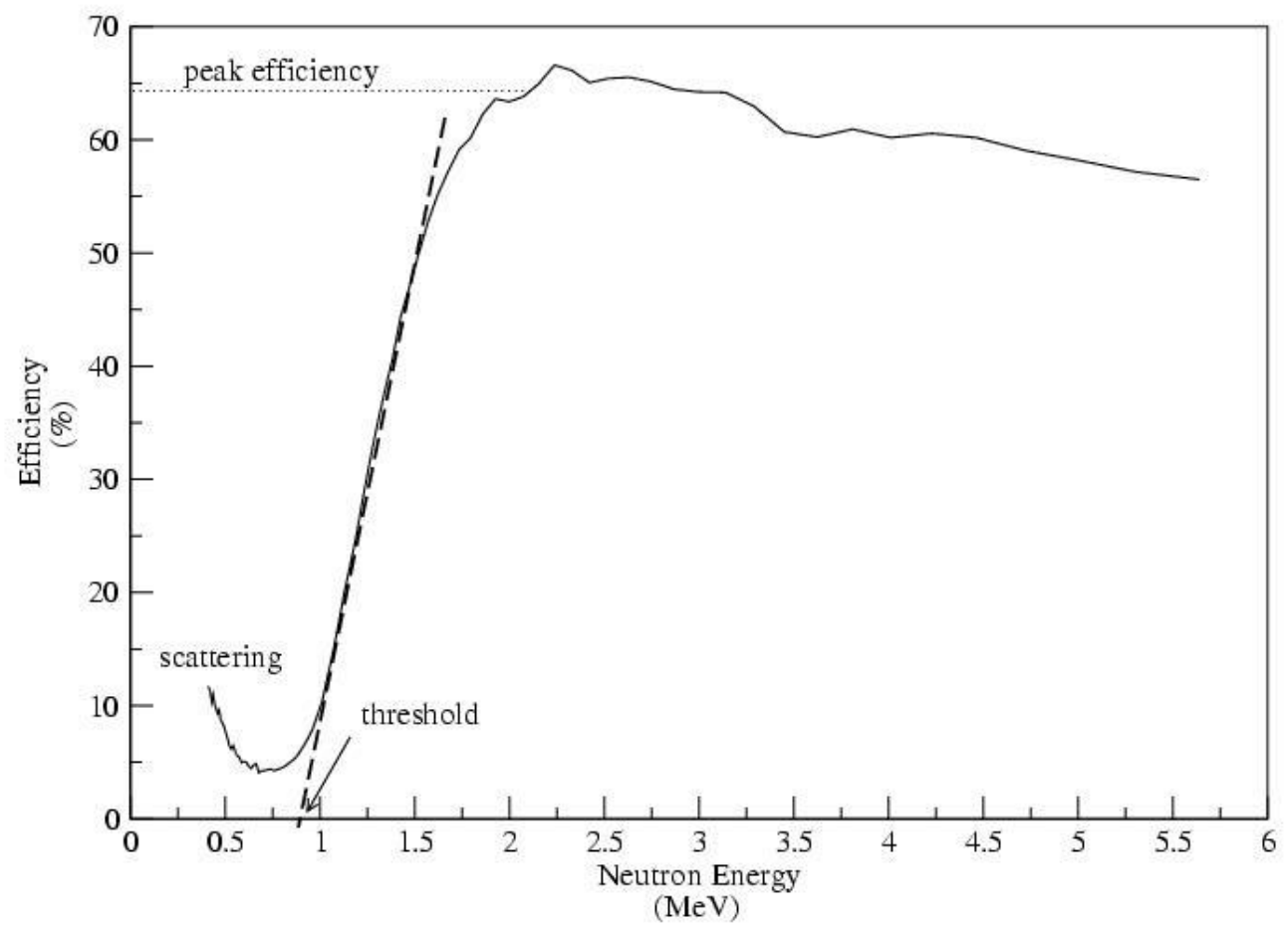

Figure 3.8. Detector Efficiency From TOF 


\section{Chapter 4}

\section{SETUP PROCEDURES}

\subsection{SETTINGS FOR THE CONSTANT FRACTION DISCRIMINATOR (CFD)}

There are four parameters that must be set correctly for proper CFD operation. First, there is an external delay cable whose length determines the delay time as described in Section 4.1.1. Also, there are three parameters on the CFD which are controlled by three potentiometers.

- Discriminator threshold (labeled T)

- Zero crossover point (labeled Z)

- Pulse width (labeled W)

The procedures to set these parameters are described in Sections 4.1.2-4.1.4.

\subsubsection{External Delay Cable}

An external delay cable must be connected between the LEMO inputs marked DLY. The length of this cable, coupled with the delay time of the CFD circuitry, controls the delay time. The correct delay time ensures that the CFD always triggers at $20 \%$ of the full amplitude of the input signal. The proper length shouldalways be calculated by measuring the rise-time of the input signal on an oscilloscope. ${ }^{14}$ In general though, the four-inch detectors require a delay of 6 nanoseconds.

1. Connect the input signal to Channel 1 of the oscilloscope and setup the following parameters.

(a) Channel 1 input $=50$ ohms.

(b) Trigger = Channel 1.

(c) Trigger slope - negative

2. Measure the rise time of the input pulse between $20 \%$ and $100 \%$ of the full amplitude as shown in Figure 4.1. Rise time of Cf ionization chamber is less than $1 \mathrm{~ns}$ and some oscilloscopes may not be capable of measuring this.

3. Using the formula in Equation (4.1), connect a delay cable (50 ohm, RG-174) of the appropriate length. 15

$$
\tau_{\text {cable }}=\mathrm{t}_{20 \% \text { to full-amplitude }}+1 \mathrm{nsec}
$$

\footnotetext{
${ }^{14}$ A 1-nes resolution on an analog oscilloscope requires a minimum bandwidth of $350 \mathrm{MHz}$.

${ }^{15}$ If unlabeled, 8 inches of RG-174 corresponds to 1 nanosecond of delay.
} 


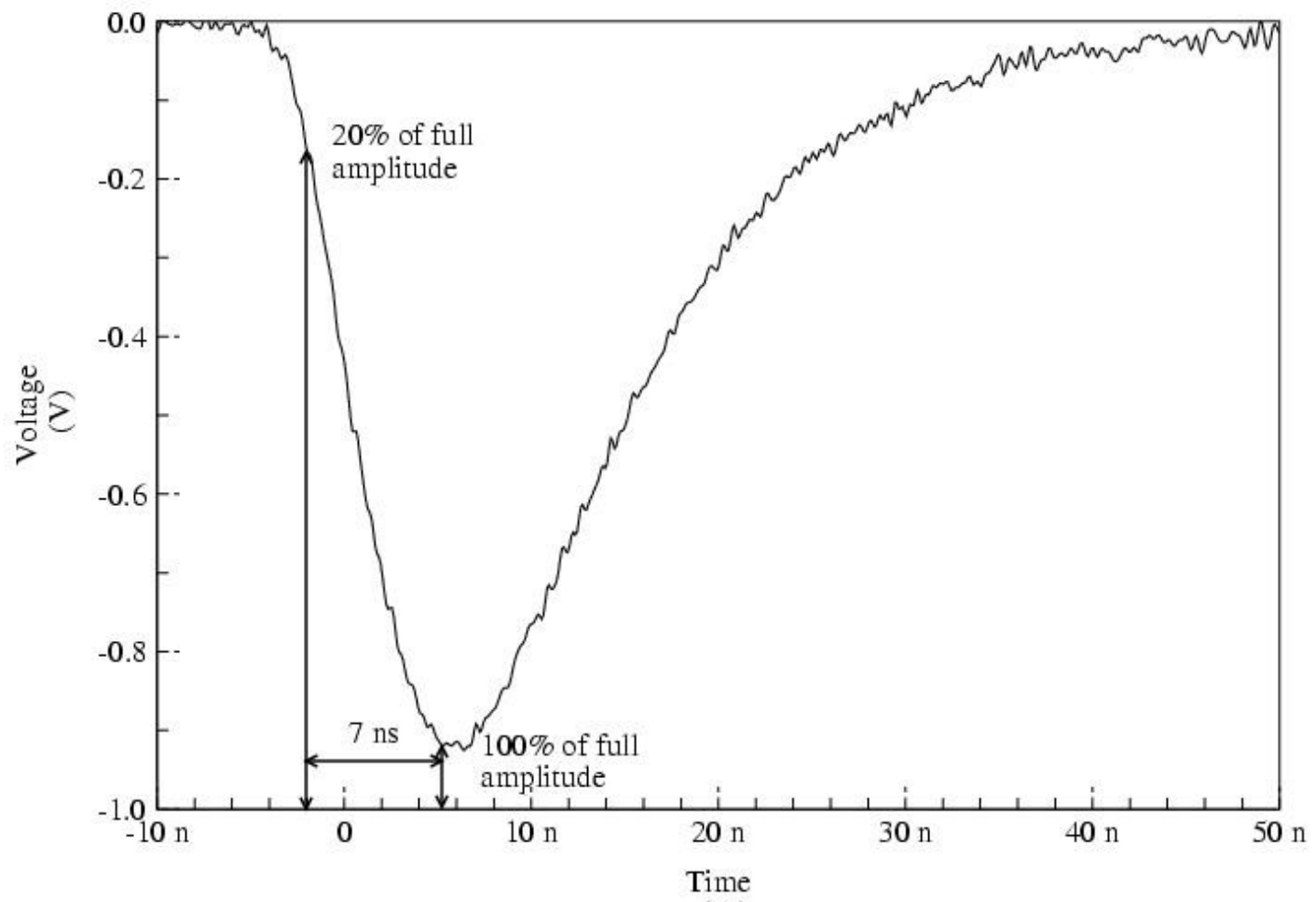

(ns)

Figure 4.1. Measurement of $20 \%$ to $100 \%$ Rise Time of Detector Pulse

\subsubsection{Threshold}

The CFD threshold is set to $-40 \mathrm{mV}(-400 \mathrm{mV}$ on the multimeter) for the detector channels. The CFD threshold for the source channel is determined by performing a pulse height curve. A pulse height curve for the source must be generated during the initial setup and whenever the source ionization chamber or amplifier is changed.

1. Connect the source to the counter as shown in Figure 4.2.

2. Set the counter/timer module to display the counts for a 10 -second period by setting the following:

(a) DISPLAY = whichever input channel you used. (For example, in Figure 4.2, Channel 3 is used as the input channel so DISPLAY should be set to 3.)

(b) $M=1$

(c) $\mathrm{N}=2$

(d) Turn off the DWELL by rotating the DWELL knob counterclockwise.

3. Using a digital voltmeter, set the voltmeter to read volts and put the black probe in one of the NIM bin GROUND test points (labeled GND) and the red probe in the CFD Threshold test point (labeled $\mathbf{T}$ ). 

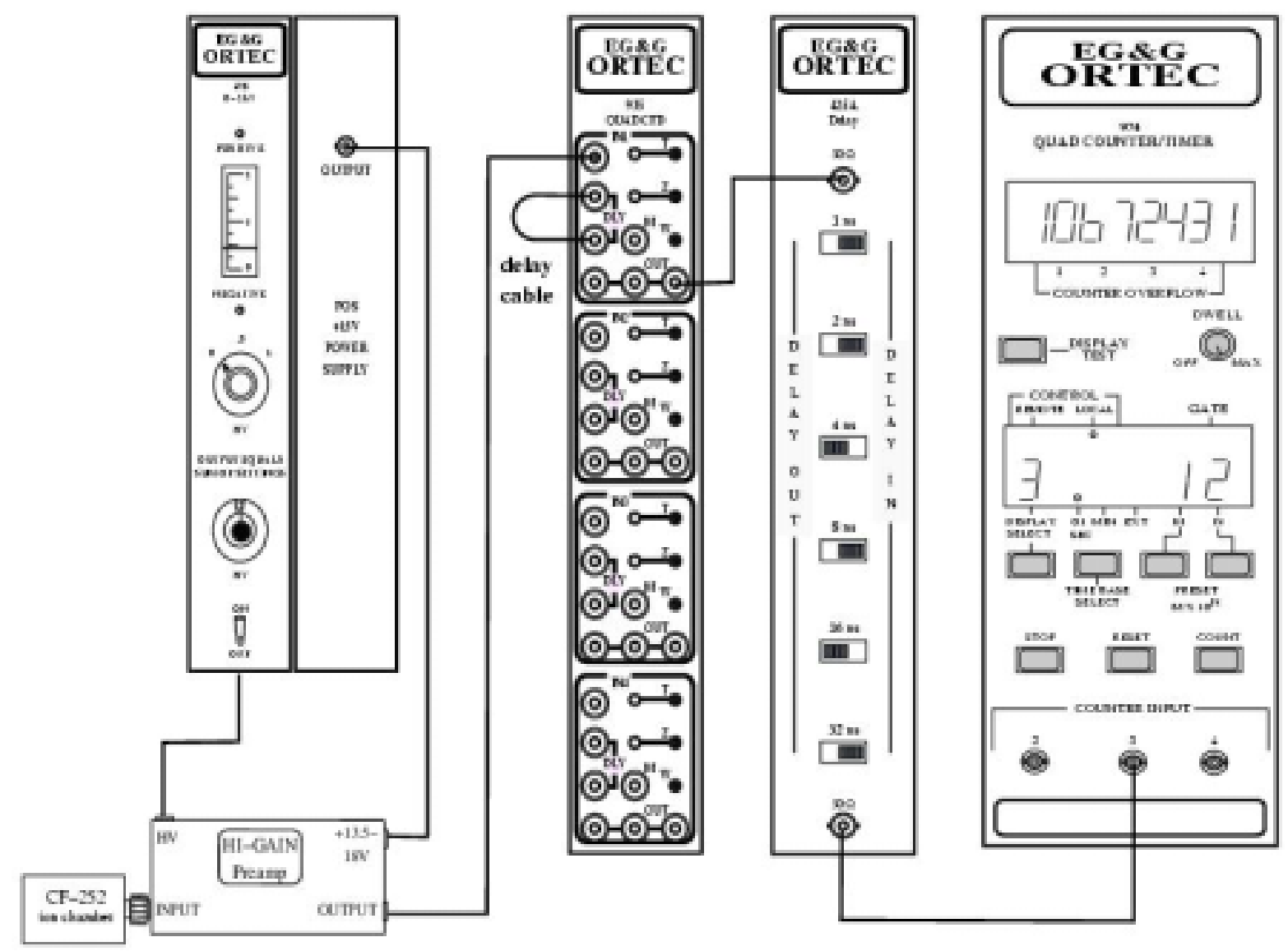

Figure 4.2. Source Connections to Generate Pulse Height Curve.

4. Beginning with a meter reading of $-400 \mathrm{mV}$ (the meter reads a factor of 10 higher than the actual threshold voltage), record the number of counts in a ten second period by pressing the RESET button followed by the COUNT button.

5. Increment the threshold voltage by $-10 \mathrm{mV}(-100 \mathrm{mV}$ on the meter) and record the counts until the threshold voltage is $-120 \mathrm{mV}(-1200 \mathrm{mV}$ on the meter $)$.

6. Plot the Count Rate vs. Threshold voltage as shown in Figure 4.3.

7. Select a discriminator voltage that is in the stable region of the counting plateau. The ideal discriminator is one that is as low as possible to maximize the source efficiency yet high enough to avoid counting the alpha pulses or electronic noise. A typical threshold value is $-80 \mathrm{mV}(-800 \mathrm{mV}$ on the multimeter). 


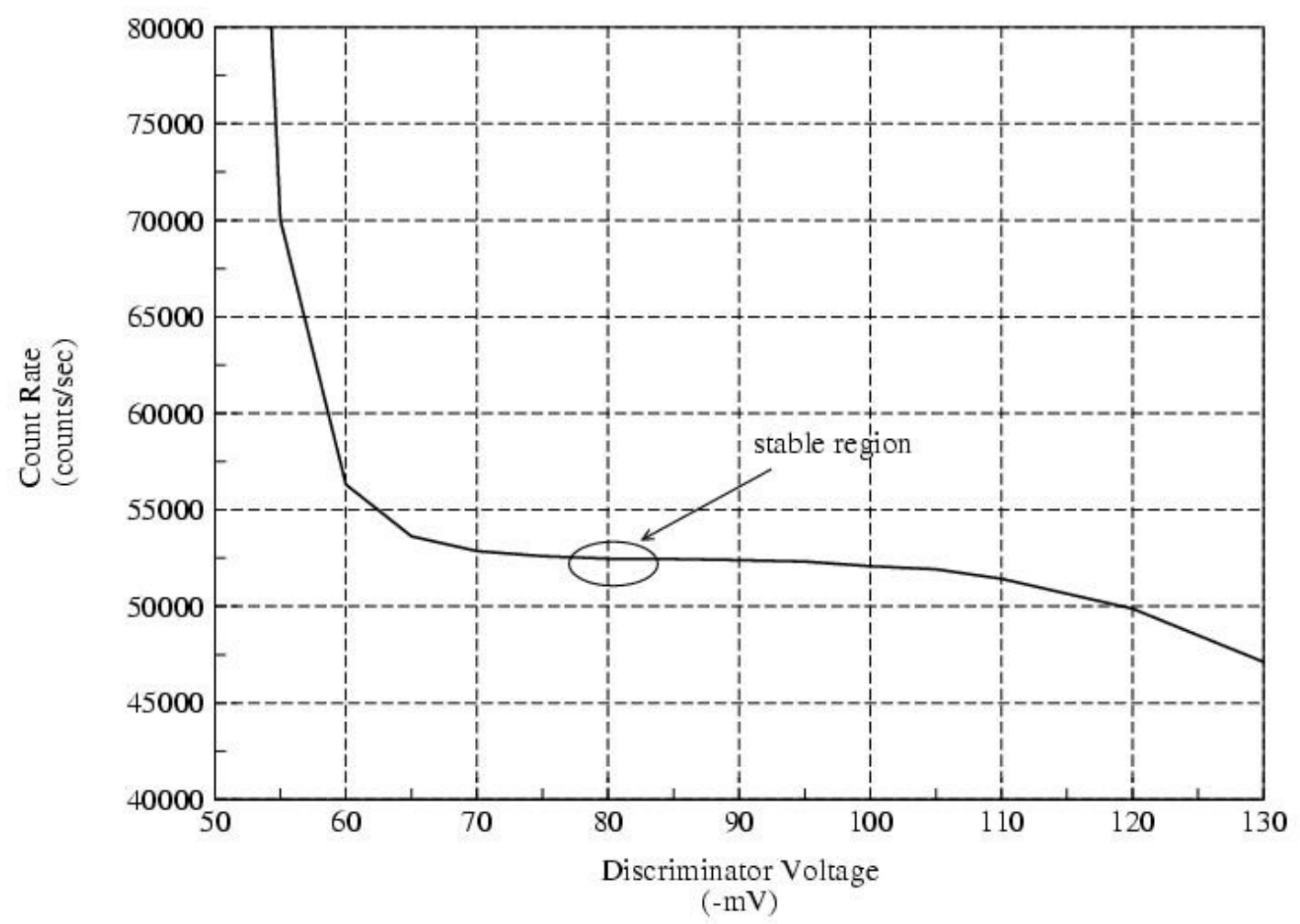

Figure 4.3. Pulse Height Curve for ${ }^{252} \mathrm{Cf}$ Source and Q6456 Amplifier

\subsubsection{Zero-Crossing}

The zero crossing potentiometer (labeled $Z$ ) is used to minimize the timing jitter of the CFD output pulse. Ideally, all the bipolar pulses will cross the zero baseline at the exact same point.

1. Connect the Monitor output (test point labeled $\mathbf{M}$ ) to Channel 1 of the oscilloscope.

2. Connect the CFD Output (any of the three test points labeled OUT) to Channel 2 of the oscilloscope. Terminate any unused outputs with 50-ohm LEMO terminators.

3. On the oscilloscope, set the following:

(a) trigger = Channel 2

(b) trigger slope $=$ negative

(c) display = Channel 1

(d) Channels 1 and 2 inputs $=50$ ohms.

4. Turn the Zero crossing potentiometer until all the bipolar Monitor pulses cross the baseline at the same point as shown in Figure 4.4. When this is done, the width of the gamma peak in the time-of-flight distribution is minimized (i.e. best time resolution). 


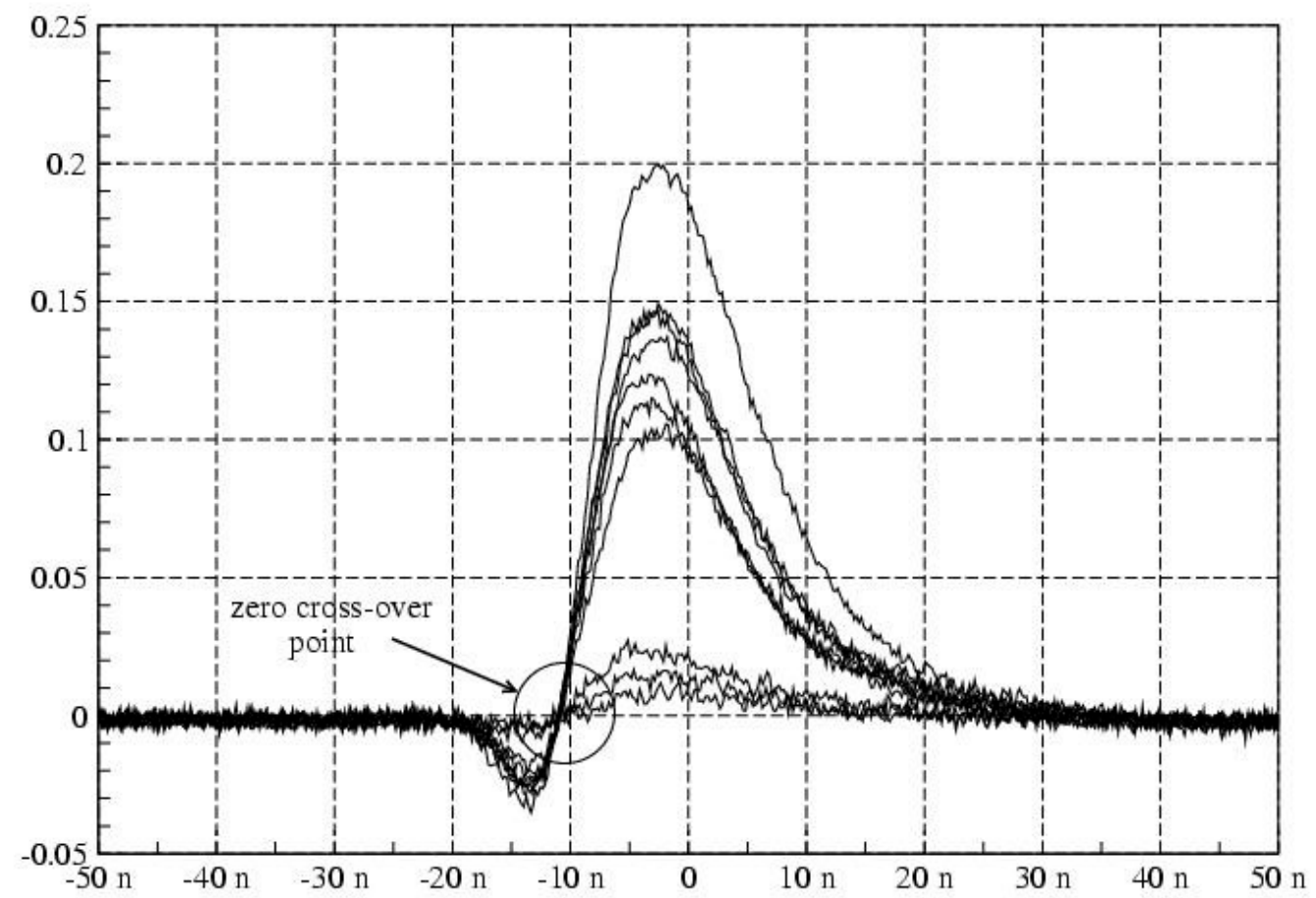

Figure 4.4. Monitor Pulses Crossing the Baseline at the Same Point

\subsubsection{Pulse Width}

The CFD is used in blocking mode, i.e., any pulses received within one pulse width of the initial pulse are ignored. Thus, to reduce system dead time, the CFD output pulse width should be as narrow as possible. However, too narrow of a pulse width can cause the CFD to double pulse on a single input pulse. This will be obvious by examining the auto correlation function of each detection channel for a TOF measurement in air. Generally, the pulse width should be set so that it is equal to or wider than the input pulses.

To properly set the CFD pulse width, perform the following steps:

1. Remove the input signal from the CFD input and reconnect it to Channel 1 of the oscilloscope.

2. Measure the width of the input pulses at the baseline.

3. Reconnect the input signal to the CFD input.

4. Connect one of the CFD outputs to Channel 1 of the oscilloscope.

(a) Channel 1 input $=50$ ohms

(b) Set the voltage scale for Channel 1 such that a $-800 \mathrm{mV}$ pulse can be observed

(c) Trigger $=$ Channel 1

(d) Trigger slope $=$ negative 
5. Adjust the width of the CFD output pulse by turning the Width potentiometer (labeled W). Set the width such that it is wider than the input signal. A pulse width of $20 \mathrm{~ns}$ is typical.

6. Check the auto correlation function for double pulsing.

\subsection{ACQUISITION OF TIME-OF-FLIGHT DATA USING DAUI}

1. Open the DAUI application.

2. Select Measurement to open a data acquisition window and verify the following settings:

- Source is Channel $A$ and Channels $A$ thru $E$ have checkmarks in ACQ (acquire) column, $(A \rightarrow E$ corresponds to detectors $1 \rightarrow 5)$

- Channels B thru $E$ have checkmarks in Comb. Multiplicity column.

- Sample rate $=1 \mathrm{GHz}$

- $\quad$ Block size $=512$ nanoseconds

- Number of Loops $=10$

- Number of blocks - 1e9

- Normal mode

- Multiplicity checkbox is checked

- HOS checkbox is checked.

3. Click on the START button.

4. Enter the file name.

\subsubsection{Verification of Gamma Peak Locations Using IDAS}

1. Open IDAS application.

2. Open appropriate file (File, Open).

3. Display positive range of all source/detector correlations:

(a) Plot, Plot Selection

(b) Select: Cross12(P), Cross13(P), Cross14(P), and Cross15(P).

4. Change range of $x$-axis (time-lags) to first 10 nanoseconds.

(a) Plot, Plot Settings

(b) User Settings button

(c) High Time Lag = 10 nanoseconds

(d) Check "Same Axis" checkbox

5. Verify that the location of the gamma peaks are $3.3 \pm 0.1$ nanoseconds using IDAS. (NOTE: 8 inches of cable corresponds to 1 nanosecond of delay.)

\footnotetext{
${ }^{16}$ If not observed, look at expanded time range.
} 
- If peaks occur too soon, lengthen the corresponding CFD output signal cable to the NMIS processor.

- If peaks occur too late, shorten the corresponding CFD output signal cable to the NMIS processor.

6. If any of the cable delays were changed, repeat steps in Sections 4.2 and 4.2.1.

\subsubsection{Verification of Detector Response Using IDAS}

1. Open the IDAS application.

2. Open the appropriate file (File, Open).

3. Display Cross Power Spectral Densities for all source/detector correlations:

(a) Plot, Plot Selection

(b) Select: CPSD12(MG), CPSD13(MG), CPSD14(MG), and CPSD15(MG).

4. Change display to linear $Y, \log X$.

5. Verify that all the CPSDs have the same amplitude for frequencies lower than $200 \mathrm{MHz}$.

- If CPSD is too high, lower voltage to PMT base.

- If CPSD is too low, lower voltage to PMT base.

6. If any of detector power supplies were adjusted, repeat steps in Sections 4.2 and 4.2.1.

\subsection{COMPUTE NEUTRON EFFICIENCY AND THRESHOLD}

Perform the following steps to verify that all the detectors have a peak efficiency of 63 $\pm 1 \%$ and a neutron threshold of $1.1 \pm 0.1 \mathrm{MeV}$.

1. In the main menu bar, select: Analysis, Detector Efficiency

2. Write efficiency parameters to efficiency.csv? = Yes (NOTE: If you get an error, then some application has it open, usually Excel. Close the efficiency.csv file and try again.)

3. Show fitted efficiency curves? = Yes or No (usually user selects NO)

- Yes: Theoretical efficiency curves will be plotted along with computed efficiency curves. Advantage: Can observe neutron thresholds better.

- No: Only computed efficiency curves are shown. Advantage: fewer curves so easier to see if efficiency data is converged.

4. Verify the following settings:

- $\quad$ Detector size = $9.52 \mathrm{~cm}$ (this assumes $3.75 " \times 3.75 " \times 4$ " detectors)

- Source/Detector Distance $=106.2 \mathrm{~cm}$ (Det. 1 and Det. 4)

- Source/Detector Distance $=104.9 \mathrm{~cm}$ (Det. 2 and Det. 3) 
- Gamma Peak Location = 3.3 (may be off by one or two nanoseconds)

- If gamma peak is off by two or more nanoseconds, hit Cancel and to back to step "Verification of Gamma Peak Locations using IDAS."

- If gamma peak location $=-512$ then the software could not find the gamma peak in which case you must manually enter the correct location of the gamma peak. (3.3 nanoseconds for 40-inch source/detector separation) WARNING: This probably is a result of an error in your setup.

- Low Energy Cutoff = $0.8 \mathrm{MeV}$

- High Energy Cutoff = $6 \mathrm{MeV}$

5. Click on the OK button.

6. Open efficiency.csv in Excel

(a) File, Open

(b) file = efficiency.csv

7. Verify that all efficiencies are $63 \pm 1$ percent:

- If efficiencies are too low, increase the high voltage to the detector.

- If efficiencies are too high, decrease the high voltage to the detector.

8. Verify that all neutron thresholds are $1.1 \pm 0.1 \mathrm{MeV}$.

9. If any of the high voltage settings were changed, go back to Section 4.2 .

10. If all detectors peak efficiencies and neutron thresholds are acceptable (peak efficiency $=63 \pm 1 \%$, neutron threshold $=1.1 \pm 0.1 \mathrm{MeV}$ ) then record the detector peak efficiencies and neutron thresholds in the logbook. 


\section{Chapter 5}

\section{OVERVIEW OF NMIS MEASUREMENTS}

The Nuclear Material Identification System (NMIS) is a computer-based correlation system composed of hardware and software components. This section outlines how to use the software components of this system. These components are needed to collect the radiation signatures that characterize an object such as a weapons component and to perform routine analysis on those signatures. The software consists of two programs, the Data Acquisition User Interface (DAUI) and the Interactive Data Analysis Software (IDAS). The first program, DAUI, is primarily used to perform all the data acquisition. The second program, IDAS, 17 is used to post-process and display the acquired data.

Other software programs that are used extensively to help analyze the data are: a spreadsheet program, Microsoft Excel, and a text editor such as Wordpad or Notepad which are all commercial software. These specific programs do not have to be used, but their functionality is required to help carry out the required data analysis.

After the initial setup, the following steps are performed:

1. Measurement of detector efficiencies

2. Scan of an item

3. Calibration of an item, and

4. Comparison and confirmation of an item against calibration database.

The first step is performed at the start of each day and prior to making any other measurements. This step is repeated until all detectors are responding within specification. The second step is performed once for each new item/container configuration or when there is concern in step 4 that the item may not be located properly in the container. Once the scan is performed and the proper height to calibrate an item is determined, then a series of calibration measurements (step 3) are performed at this height for future reference. These set of references form the calibration database to which items are compared in verifications of inventories and receipts.

\subsection{SCAN OF AN ITEM}

Every unique configuration of an item in a container must be scanned in order to identify the appropriate location for the calibration measurement. This measurement is base upon attenuation of the gamma and neutron radiation emitted from the ${ }^{252} \mathrm{Cf}$ source. The containerized item is scanned from bottom to top (or vice versa) and the integrated counts in the gamma and/or neutron peak of the source-detector correlation are plotted against the scan height. Figure 5.1 shows the source and detectors positioned around a containerized item at one of the scan position. Note that the source is aligned with the bottom detector. 18 If possible, the same detector should be used throughout the scan.

\footnotetext{
${ }^{17}$ This program is also referred to as ANWIS.

${ }^{18}$ Color-coded red.
} 


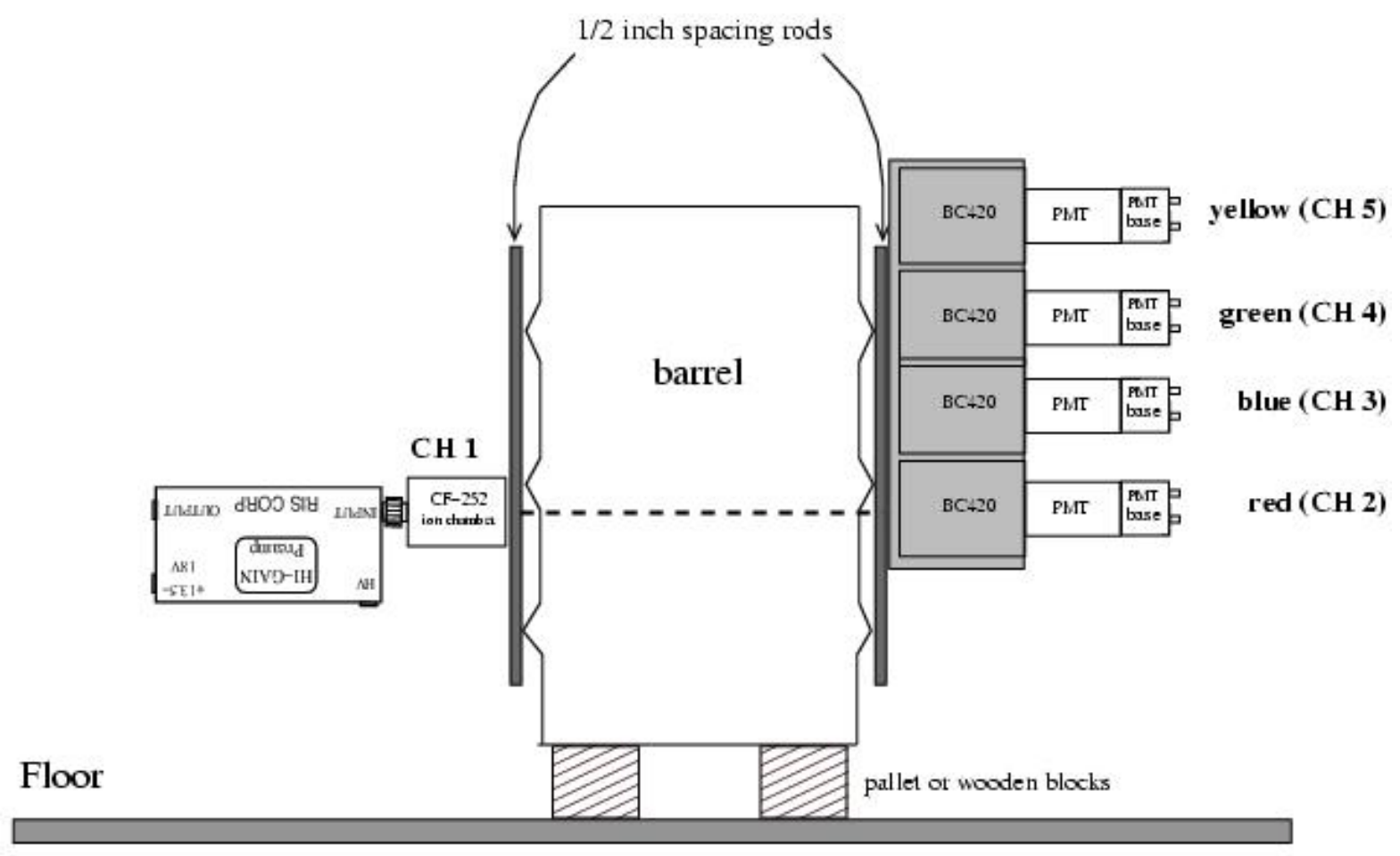

Figure 5.1. Generic Source/Detector Setup for Scan of Containerized Item (Spacing rods removed for measurements.)

There are two scan resolutions, coarse and fine. Coarse scan means that the source and detectors are moved in one inch increments which is typically performed near the bottom and top of the container. For fine scans, the source and detector are moved in 1/2-inch increments. A fine scan is typically performed in the neighborhood of the expected measurement location for the item.

\subsection{CALIBRATION OF AN ITEM}

Currently, twelve measurements for each unique combination of an item and container form a reference class and are grouped together in a reference catalog. For example, Item A in a DT-20 will have a different reference class than Item A in a DT-99. These catalogs form the calibration database from which future items are compared. The size of the reference class may be expanded in the future.

The source and detector stack are placed on opposite sides of the item, 180 degrees apart as shown in Figure 5.1. The source and calibration detector (2nd detector from the bottom) are set at the height determined from the vertical scan. A calibration measurement is performed twelve times. The length of time of the calibration measurement is determined by the convergence of the neutron peak in the source-detector correlation signature. Typical calibration times are less than 1 hour.

To explain how the twelve measurements are grouped, assume that Item $A$ is containerized in a DT-99. Three cans of Item A (in DT-99's) are randomly pulled from storage for measurement as shown in Figure 5.3. For each can, four measurements at four different positions are performed. Thus, three cans times four measurements per can equals twelve measurements. This reference class is stored in a catalog file, A-ref.cat. 
A whole set of reference classes, for example, all of the inventory reference measurements for a vault, can be defined as a reference file. This reference file is an ASCII text file like the catalog file and has a .ref extension in the file name. In our example, it could be Vault.ref. This file contains the names of all the catalog files that form the reference database.

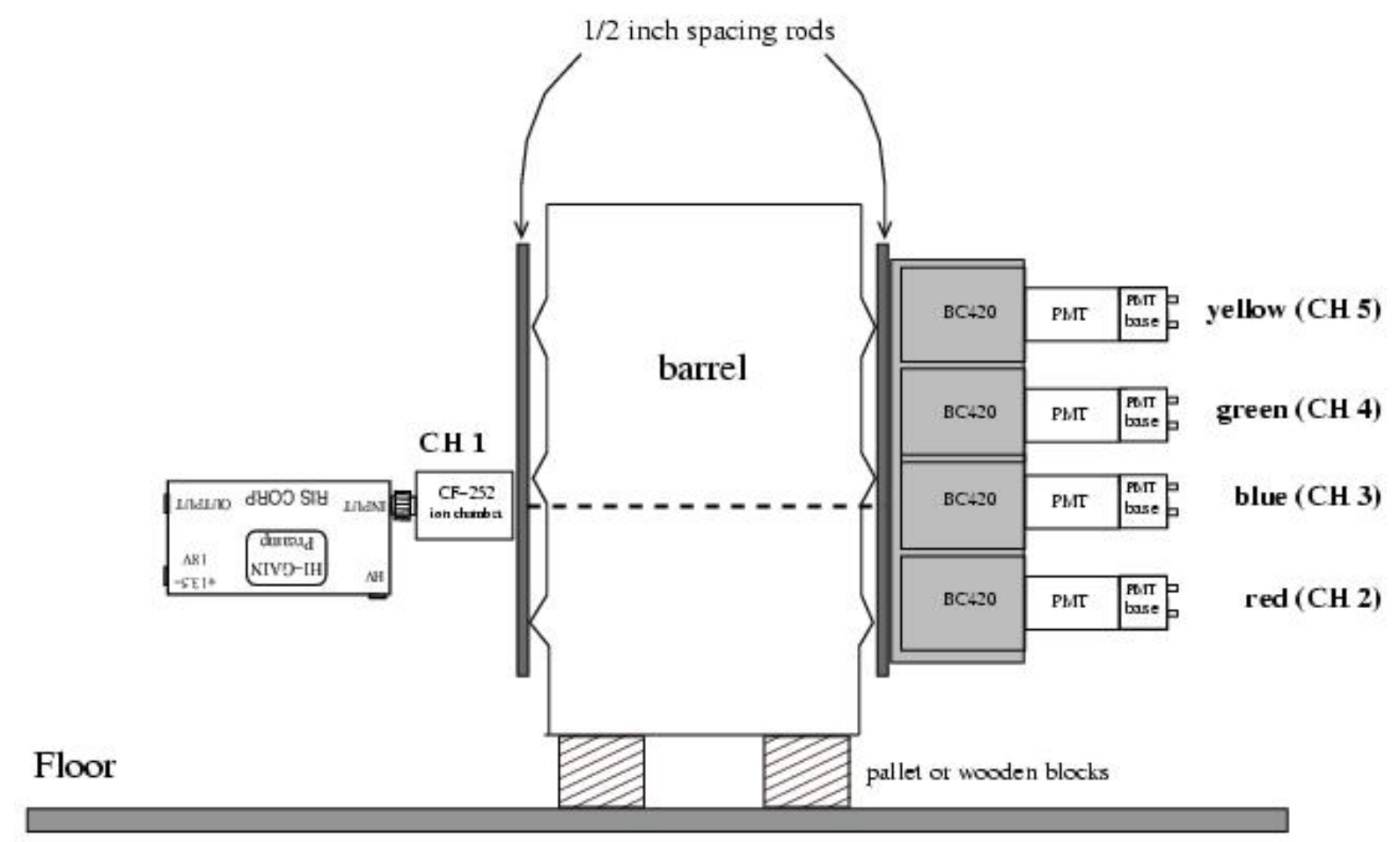

Figure 5.2. Generic Source/Detector Setup for Calibration Measurements (Spacing rods removed for measurements.)

\subsection{COMPARISON AND CONFIRMATION OF AN ITEM}

NMIS can compare an item against any reference class in the calibration database. At present, the user visually compares the cross power spectral densities (CPSD12(MAG), CPSD13(MAG), CPSD14(MAG), CPSD15(MAG) and the cross correlations (CROSS12, CROSS13, CROSS14, CROSS15) with those in the reference class of interest.

The basic procedure is best explained with an example. Assume that there are three references, A.cat, B.cat, and C.cat. These references are all listed in our reference database as Vault.ref. Furthermore, there is an item that has been declared Type A so we want to compare it to A.cat using four detectors. The following steps outline how to compare the unknown against the declared type using CPSD13.

1. Setup source and detectors as described in Section 5.2.

2. Measure unknown item for 5-10 minutes. 


\section{4 measurements}

\section{4 measurements}

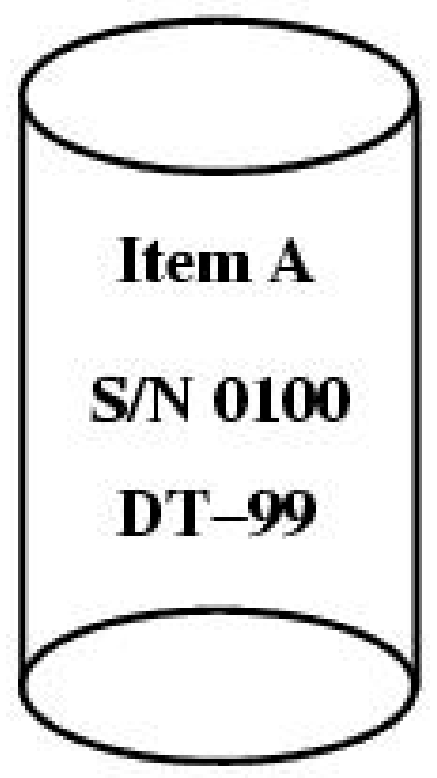

\section{4 measurements}

Item A

S/N 2341

DT-99

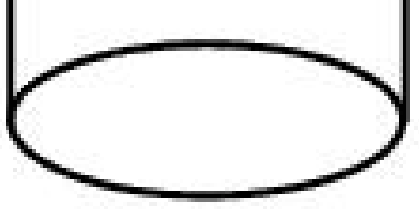

12 measurements

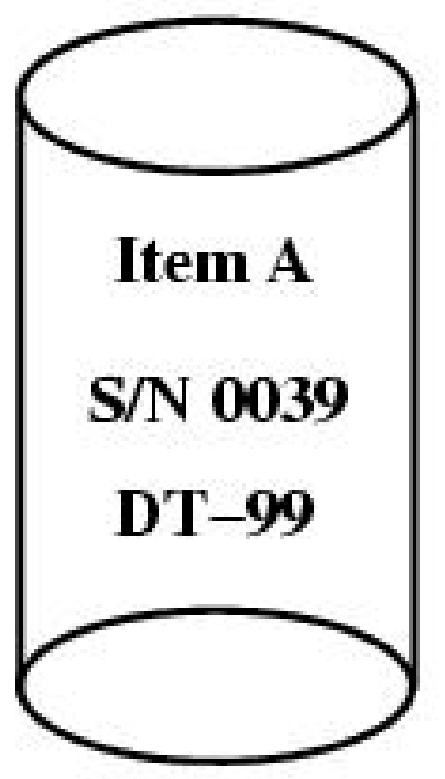

$$
\text { A-ref.cat }
$$

Figure 5.3. Formation of a Reference Catalog

3. Load unknown measurement (File, Open).

4. Load reference measurements.

- $\quad$ Select Matching on main menu bar.

- $\quad$ Select Load references.

- In the file selection dialog box, select Vault.ref. 
5. Select NMIS signature for comparison.

- Plot, Plot Selection

- CPSD $_{13}$

6. Select default reference to compare unknown against:

- Select Matching in the main menu bar.

- All the references in Vault.ref should appear, select A-ref.cat.

7. Compare unknown against reference using Ratio-to-reference (Display, Ratio to Reference), or

8. Display unknown against the bounds of the reference signature:

- On the main menu bar, select Plot,

- Plot Selections,

- Select Show bounds.

9. For the Ratio-to-reference and Show bounds methods, if the majority of the low frequency points fall inside the band, then the item probably is a member of that reference class.

\section{WARNING!}

For best results, both the time domain and frequency domain signatures should be compared against their reference signatures. Compare both CPSD13 and CROSS13 to avoid dominance of either the gamma or neutron peaks to determine the match.

For subsequent comparisons, the next unknown should be read into IDAS (File, Read). If you close the previous measurement, and then load the new unknown (using File, Open), then all of the references will also have to be re-loaded. 


\section{Chapter 6}

\section{TROUBLE SHOOTING TIPS}

\subsection{GENERAL}

This section gives general trouble shooting guidance. Before beginning extensive trouble shooting, it is important to remember that the electronics equipment, including the detectors and the ionization chamber amplifier, need time to stabilize. A warm-up period of at least half-day especially for the scintillation detector power supplies is advised prior to checking detector efficiencies and neutron energy detection thresholds.

Table 6.1. Some Trouble Shooting Tips

\begin{tabular}{|c|c|}
\hline Symptom & Solution \\
\hline $\begin{array}{l}\text { APSDs are not flat } \\
\text { Auto correlation function show multiple } \\
\text { pulses }\end{array}$ & $\begin{array}{l}\text { Ringing in base - replace base. } \\
\text { Reflection in cables - replace cable. }\end{array}$ \\
\hline Correlations are incorrect in IDAS & $\begin{array}{l}\text { Verify that Channel } 1 \text { is the source. Look at } \\
\text { NMIS processor input - Channel } 1 \text { is closest } \\
\text { to the power supply connector. }\end{array}$ \\
\hline Counter doesn't count & $\begin{array}{l}\text { Counter is shipped with default jumper setting } \\
\text { to count positive pulses. Set to negative. }\end{array}$ \\
\hline $\begin{array}{l}\text { Detector efficiency is much lower or } \\
\text { higher than expected }\end{array}$ & $\begin{array}{l}\text { Incorrect source-detector distance, or } \\
\text { incorrect detector size specified in analysis or } \\
\text { incorrect voltage. }\end{array}$ \\
\hline Detector efficiencies are drifting & $\begin{array}{l}\text { Detectors and high voltage power supplies } \\
\text { are not warmed up, or high voltage power } \\
\text { supply is defective. }\end{array}$ \\
\hline $\begin{array}{l}\text { External NMIS power supply is not } \\
\text { working (all LEDs are not lit). }\end{array}$ & $\begin{array}{l}\text { Make sure that the computer is turned on } \\
\text { before turning on power supply. }\end{array}$ \\
\hline Gamma peak is wider than usual & Zero crossing in CFD needs to be adjusted. \\
\hline $\begin{array}{l}\text { Multimeter readings drift when measuring } \\
\text { Threshold on CFD }\end{array}$ & $\begin{array}{l}\text { Ground test point failed on CFD, use GND } \\
\text { test point on NIM bin. }\end{array}$ \\
\hline NIM bin electronics don't operate properly & $\begin{array}{l}\text { The } 4002 \text { Nim bin power supply can only } \\
\text { support two CFDs. }\end{array}$ \\
\hline \multirow[t]{2}{*}{ No detector input signal } & $\begin{array}{l}\text { PMT base or high voltage power supply } \\
\text { failed. }\end{array}$ \\
\hline & Cable failed \\
\hline No source input signal & $\begin{array}{l}\text { Amplifier or }+15 \text { VDC power supply failed. } \\
\text { Cable failed. }\end{array}$ \\
\hline Amplifier keeps failing & $\begin{array}{l}\text { Check that the maximum input voltage is } \\
+200 \text { VDC. The amplifier is sensitive to } \\
\text { mechanical shock, so turn off the bias supply } \\
\text { when moving the source. }\end{array}$ \\
\hline
\end{tabular}


Table 6.1. Some Trouble Shooting Tips (Cont'd.)

\begin{tabular}{|l|l|}
\hline \multicolumn{1}{|c|}{ Symptom } & \multicolumn{1}{c|}{ Solution } \\
\hline Red LED on CFD is off & $\begin{array}{l}\text { No input signal. Check cables. Verify input } \\
\text { signals with oscilloscope. }\end{array}$ \\
\hline Source count rate suddenly varies & $\begin{array}{l}\text { Contacts in ionization qhamber are not } \\
\text { making proper contact. }\end{array}$ \\
& $\begin{array}{l}\text { the source amplifier. Disconnect the source } \\
\text { from the amplifier. Gently push together, the } \\
\text { contacts in the ionization chamber connector } \\
\text { with a small screwdriver. }\end{array}$ \\
\hline TOF spectrum is flat & No source input signal. \\
\hline
\end{tabular}

\subsection{MATCHING}

In the event of a mismatch between an inspected container's declared contents and the identification made by NMIS, verify the correct configuration of the inspection measurement by following the subsequent checklist. Also, verify that you are comparing to the right reference files. After completing each major step (first level check), if any deficiency in the configuration of the measurement is discovered it should be corrected, and the inspection measurement should be repeated to determine if correction of the deficiency has resolved the mismatch.

1. Verify that all instrumentation and supporting electronics are operational and properly connected.

(a) Verify that the NMIS processor power supply is operational and is properly connected to the NMIS processor.

(b) Verify that the source CFD channel is operational and is properly connected to the NMIS processor.

(c) Verify that each detector's CFD channel is operational and is properly connected to the NMIS processor.

(d) Verify that the source CFD channel is properly connected to the source amplifier.

(e) Verify that each detector's CFD channel is properly connected to the correct detector PMT base.

(f) Verify that the source amplifier DC supply is operational and is properly connected to the source amplifier.

(g) Verify that the source bias supply is operational and is properly connected to the source amplifier.

(h) Verify that the source ionization chamber is properly connected to the source amplifier.

(i) Verify that the source ionization chamber SMA connector is making contact with its mating connector on the source amplifier (applies only to source ionization chambers lacking an integrated BNC connector).

\footnotetext{
${ }^{19}$ This only applies to ionization chambers with the small SMA type connectors.
} 
- Prior to performing this step, de-energize and disconnect both the source bias supply and the source amplifier DC supply from the source amplifier. Only after the source bias supply and the source amplifier DC supply have been de-energized and disconnected from the source amplifier may the source ionization chamber be disconnected from the source amplifier to allow visual inspection of the source ionization chamber SMA connector.

- Upon completion of this inspection, reconnect the source ionization chamber to the source amplifier, ensure that the source bias supply and the source amplifier DC supply are properly reconnected to the source amplifier, ensure that both are re-energized, and verify their operation and proper connection to the source amplifier.

(j) Verify that each detector's high voltage supply is operational and is properly connected to the correct detector PMT base.

(k) Verify that each detector's PMT base is properly connected to its PMT.

2. Verify that the instruments are properly positioned with respect to the container.

(a) Verify that the source is at the correct elevation.

(b) Verify that the detector array is at the correct elevation.

(c) Verify that the detector array is right side up.

(d) Verify that the source is aligned with the correct detector.

(e) Verify that the line of sight between the source and the detector with which it is aligned intersects the container's central axis.

(f) Verify that the standoff distance between the source and the container is correct.

(g) Verify that the standoff distance between the detector array and the container is correct.

3. Verify that the instruments' supporting electronics are properly configured.

(a) Verify that each CFD channel's shaping delay, threshold, zero, width, and synchronization delay are set to their correct values as recorded during the most recent diagnostic time-of-flight measurement (refer to $§ 4.2$ of the NMIS Operational Manual).

(b) Perform a new diagnostic time-of-flight measurement according to $\S 4.2$ of the NMIS Operational Manual and examine the following:

- Verify that each detector's synchronization delay has not significantly changed.

- Verify that the each detector's peak neutron efficiency and neutron threshold has not significantly changed.

- Verify that each detector's dead time has not significantly changed.

- Verify that the source count rate has not significantly changed.

- Verify that the source's dead time has not significantly changed.

- Verify that the source CFD channel is not double pulsing.

4. Verify that the inspected component is normally positioned within its container. 
(a) Perform an axial scan (see Figure 6.1) of the container to locate the axial position of the object within the container; verify that the instrumentation is nominally positioned about the axial position of the object within the container.

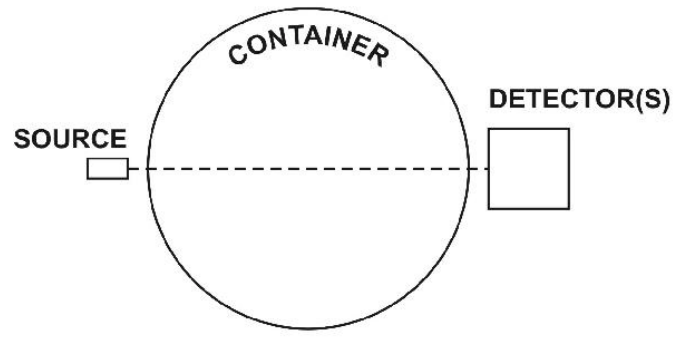

PLAN VIEW

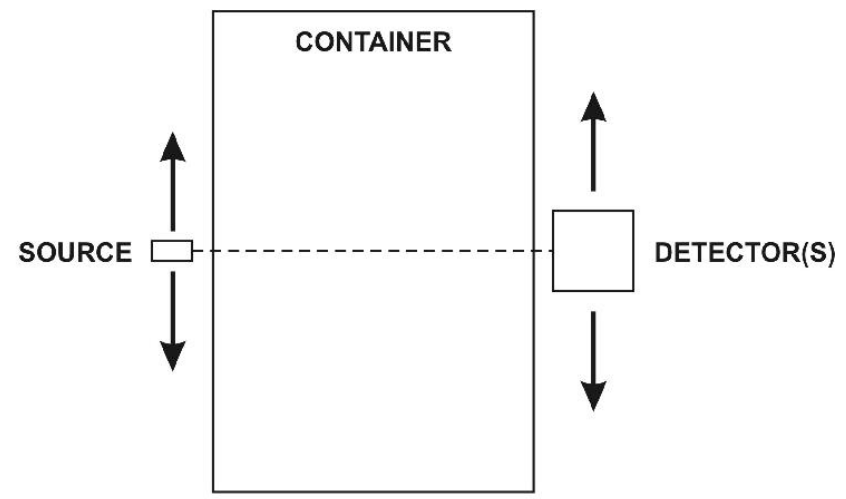

ELEVATION VIEW

Figure 6.1. Axial Scan of the Container

(b) Perform a transverse scan (see Figure 6.2) of the container to locate the object's transverse position within the container of the component; if physical constraints prevent a horizontal scan, perform a polar scan of the container (see Figure 6.3) to locate the transverse position of the object. Verify that the instrumentation is nominally positioned about the object's transverse position.

(c) Note that significant deviations in the component's position within its container should be reported to Packaging as they indicate a deficiency in the inspected container's configuration.

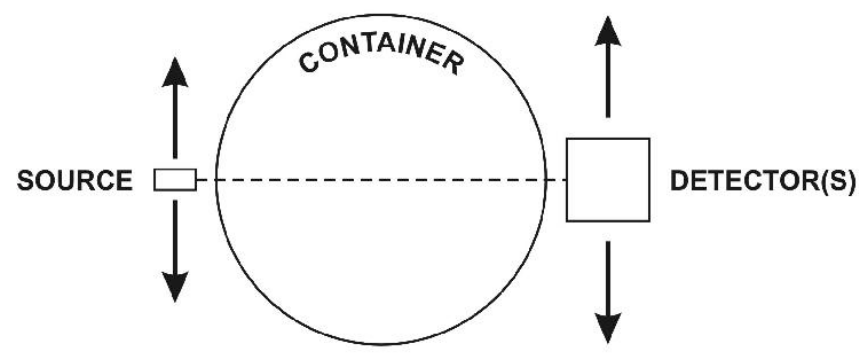

PLAN VIEW

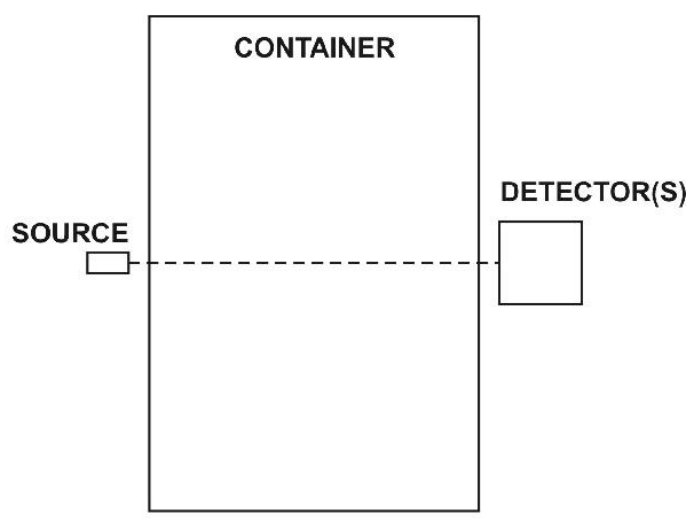

ELEVATION VIEW

Figure 6.2. Transverse Scan of the Container 


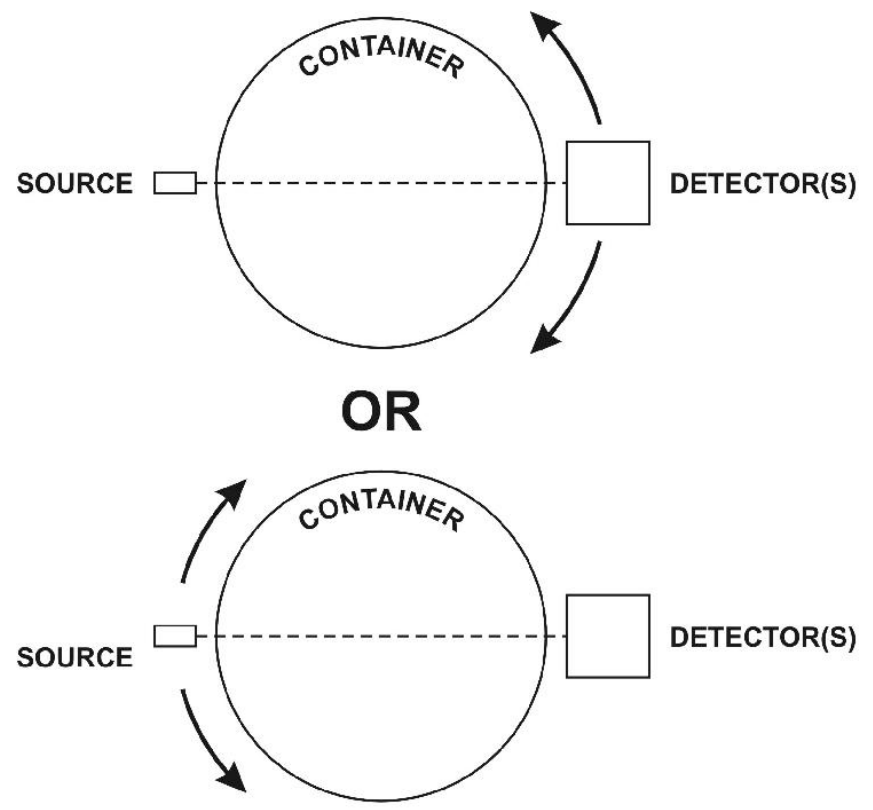

PLAN VIEW

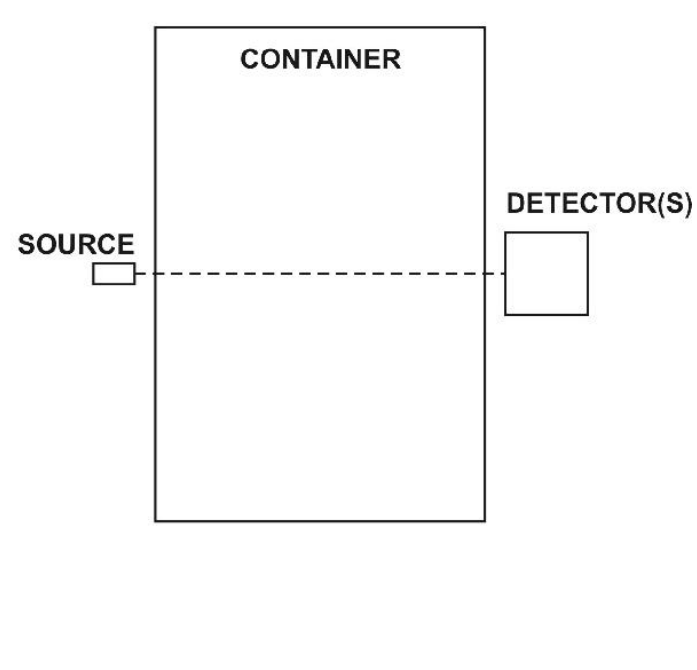

ELEVATION VIEW

Figure 6.3. Polar Scan of the Container 


\section{Conclusions}

This report has provided information so that the NMIS hardware can be setup for proper use at the Oak Ridge Y-12 Plant. 
Appendix A

The Effect of Voltage and Discriminator Level on Detection Efficiency 


\section{The Effect of Voltage and Discriminator Level on Efficiency}

A set of measurements was performed with $\mathrm{NMIS}^{54}$ to study the effect of voltage and discriminator level on detection efficiency and neutron energy threshold. Source-detector time of flight data was acquired using a single $4 \times 4 \times 4$ inch detector. The voltage on the PMT tube was varied from 1460 to $1600 \mathrm{~V}$ and discriminator level was varied from $30 \mathrm{mV}$ to 100 $\mathrm{mV}$. Figure A.1 shows the time of flight for fixed voltage $(1500 \mathrm{~V})$ and varying CFD level. Figure A.2 shows the time of flight for fixed CFD level $(40 \mathrm{mV})$ and varying voltage.

Table A.1 gives the values of the neutron and photon peak areas of the covariance function, whereas Table A.2 gives the values of the maximum detection efficiency for neutrons and neutron energy threshold for varying voltage and CFD level. A graphical representation of this data is given in Figures A.3 and A.4. These data can be useful in setting up the proper detection efficiency for a measurement. The normal setting on the CFDs is $40 \mathrm{MV}$. These data show the correspondence between photomultiplier tube voltage and the CFD threshold. For example, a neutron energy detector threshold of $1 \mathrm{MeV}$ and maximum neutron efficiency of $57 \%$ can be obtained with thresholds and voltages on the photomultiplier tube of: $30 \mathrm{mV}$, $1460 \mathrm{~V} ; 40 \mathrm{mV}, 1500 \mathrm{~V} ; 60 \mathrm{mV}, 1550 \mathrm{~V}$; or $80 \mathrm{mV}, 1600 \mathrm{~V}$.

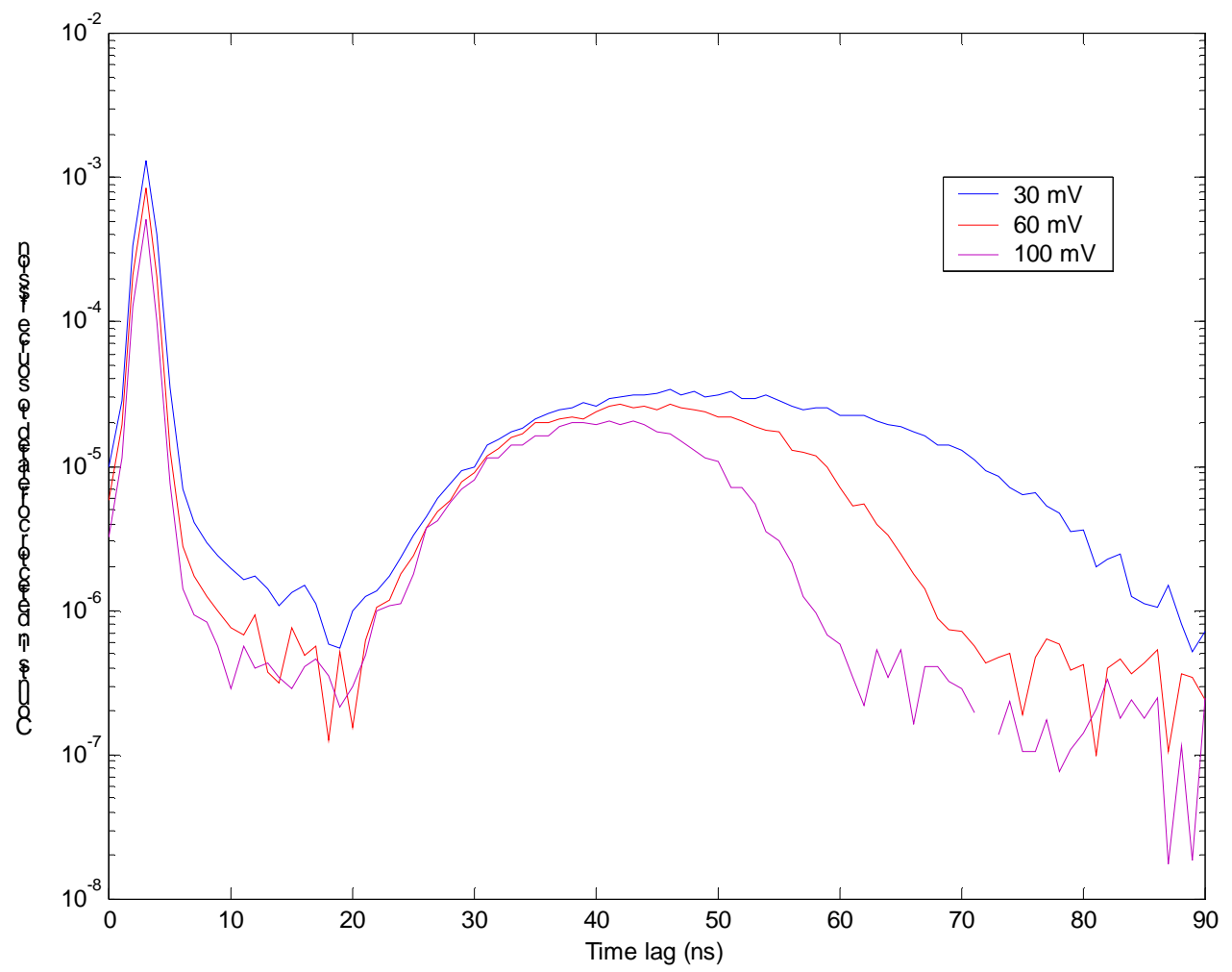

Figure A.1. Time of flight for source and detector for different CFD levels: 30, 60, and $100 \mathrm{mV}$. Voltage was kept constant at $1500 \mathrm{~V}$. 


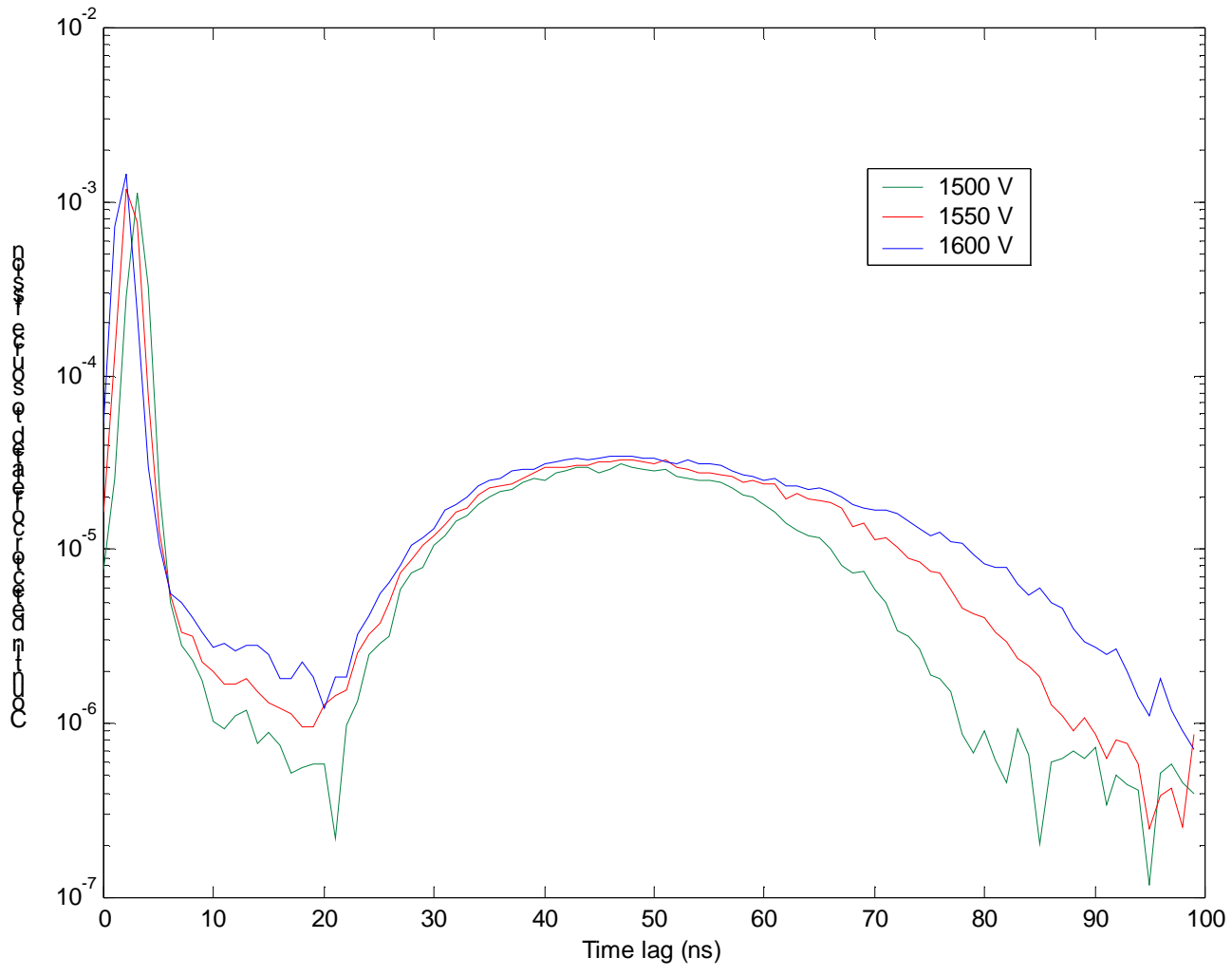

Figure A.2. Time of flight for source and detector for different voltages: 1500, 1550, and $1600 \mathrm{~V}$. CFD level was kept constant at $40 \mathrm{mV}$. 
Table A-1a: Neutron Peak Area

\begin{tabular}{ccccc}
\hline $\begin{array}{c}\text { CFD } \\
\text { Discriminator } \\
\text { Threshold } \\
(\mathbf{m V})^{\mathbf{a}}\end{array}$ & \multicolumn{4}{c}{ PMT Voltage (volts) } \\
\cline { 2 - 5 } & $\mathbf{1 4 6 0}$ & $\mathbf{1 5 0 0}$ & $\mathbf{1 5 5 0}$ & $\mathbf{1 6 0 0}$ \\
\hline $\mathbf{3 0}$ & 0.9115 & 1.1040 & 1.3114 & 1.4863 \\
$\mathbf{4 0}$ & 0.7224 & 0.9036 & 1.1316 & 1.3313 \\
$\mathbf{6 0}$ & 0.4926 & 0.6594 & 0.8859 & 1.0877 \\
$\mathbf{8 0}$ & 0.3603 & 0.5003 & 0.7108 & 0.9153 \\
$\mathbf{1 0 0}$ & 0.2647 & 0.3988 & 0.5797 & 0.7911 \\
\hline
\end{tabular}

${ }^{a}$ Actual threshold setting given here is a factor of 10 lower than the readout by a voltmeter at the threshold measuring point of the CFD.

Table A-1b: Photon Peak Area

\begin{tabular}{cllll}
\hline $\begin{array}{c}\text { CFD } \\
\text { Discriminator } \\
\text { Threshold } \\
(\mathbf{m V})^{\mathbf{a}}\end{array}$ & \multicolumn{4}{c}{ PMT Voltage (volts) } \\
\cline { 2 - 5 } & $\mathbf{1 4 6 0}$ & $\mathbf{1 5 0 0}$ & $\mathbf{1 5 5 0}$ & $\mathbf{1 6 0 0}$ \\
\hline $\mathbf{3 0}$ & 1.7854 & 2.1328 & 2.4892 & 2.7434 \\
$\mathbf{4 0}$ & 1.4207 & 1.7888 & 2.1929 & 2.4994 \\
$\mathbf{6 0}$ & 0.9543 & 1.2961 & 1.7545 & 2.1114 \\
$\mathbf{8 0}$ & 0.6767 & 0.9789 & 1.4161 & 1.7874 \\
$\mathbf{1 0 0}$ & 0.5187 & 0.7621 & 1.1452 & 1.5479 \\
\hline
\end{tabular}

${ }^{2}$ Actual threshold setting given here is a factor of 10 lower than the readout by a voltmeter at the threshold measuring point of the CFD.
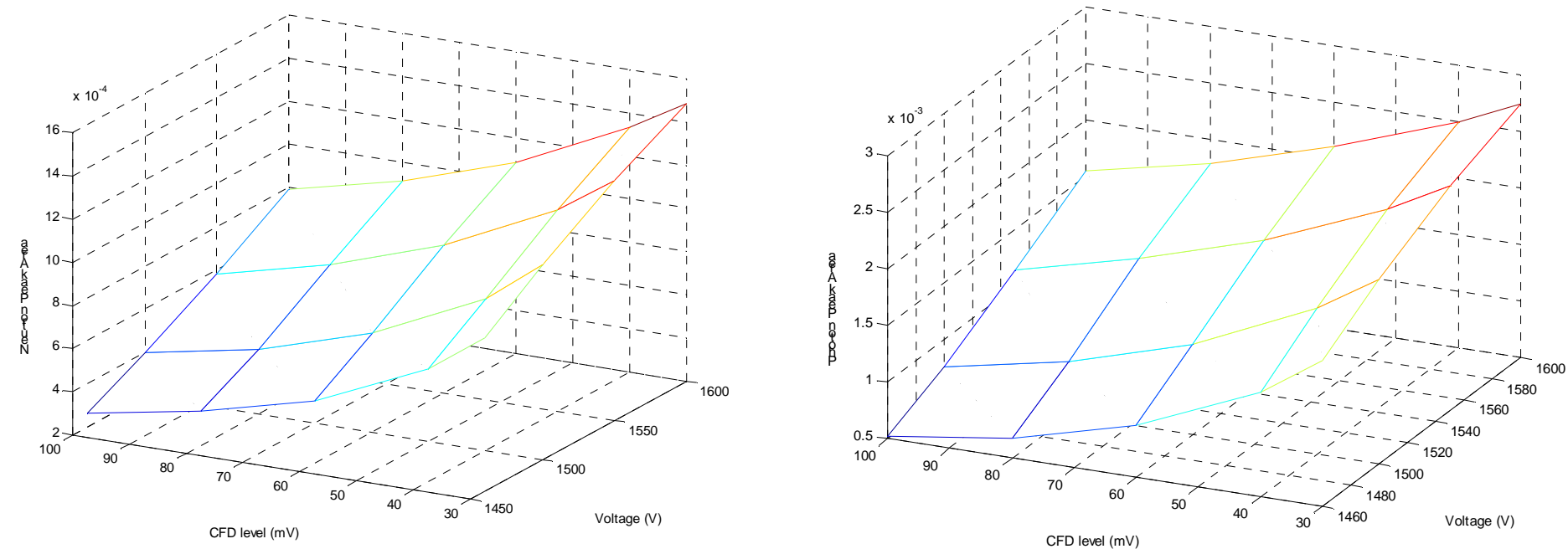

Figure A.3. Neutron peak area and photon peak area as a function of CFD level (mV) and voltage (V). 
Table A-2a: Maximum Neutron Efficiency (\%)

\begin{tabular}{ccccc}
\hline $\begin{array}{c}\text { CFD } \\
\text { Discriminator } \\
\text { Threshold } \\
(\mathbf{m V})^{\mathbf{a}}\end{array}$ & \multicolumn{4}{c}{ PMT Voltage (volts) } \\
\cline { 2 - 5 } & $\mathbf{1 4 6 0}$ & $\mathbf{1 5 0 0}$ & $\mathbf{1 5 5 0}$ & $\mathbf{1 6 0 0}$ \\
\hline $\mathbf{3 0}$ & 57.8513 & 65.1891 & 72.8036 & 78.6415 \\
$\mathbf{4 0}$ & 50.7374 & 57.3822 & 65.5562 & 72.9178 \\
$\mathbf{6 0}$ & 41.2319 & 47.5520 & 57.5046 & 64.2964 \\
$\mathbf{8 0}$ & 35.3409 & 41.7120 & 50.3026 & 57.8759 \\
$\mathbf{1 0 0}$ & 30.5681 & 37.5143 & 44.7041 & 53.6435 \\
\hline
\end{tabular}

${ }^{\mathrm{a} A c t u a l}$ threshold setting given here is a factor of 10 lower than the readout by a voltmeter at the threshold measuring point of the CFD.

\begin{tabular}{ccccc}
\multicolumn{3}{c}{ Table A-2b: Neutron Energy Threshold (MeV) } \\
\hline $\begin{array}{c}\text { CFD } \\
\text { Discriminator } \\
\text { Threshold } \\
(\mathbf{m V})^{\mathbf{a}}\end{array}$ & \multicolumn{5}{c}{ PMT Voltage (volts) } \\
\cline { 2 - 5 } & $\mathbf{1 4 6 0}$ & $\mathbf{1 5 0 0}$ & $\mathbf{1 5 5 0}$ & $\mathbf{1 6 0 0}$ \\
$\mathbf{3 0}$ & 0.9900 & 0.8655 & 0.7526 & 0.6879 \\
$\mathbf{4 0}$ & 1.1768 & 1.0167 & 0.8555 & 0.7579 \\
$\mathbf{6 0}$ & 1.5167 & 1.2376 & 1.0155 & 0.8690 \\
$\mathbf{8 0}$ & 1.8214 & 1.5021 & 1.1872 & 0.9943 \\
$\mathbf{1 0 0}$ & 2.0514 & 1.7221 & 1.3182 & 1.1054 \\
\hline
\end{tabular}

${ }^{\mathrm{a} A c t u a l}$ threshold setting given here is a factor of 10 lower than the readout by a voltmeter at the threshold measuring point of the CFD.
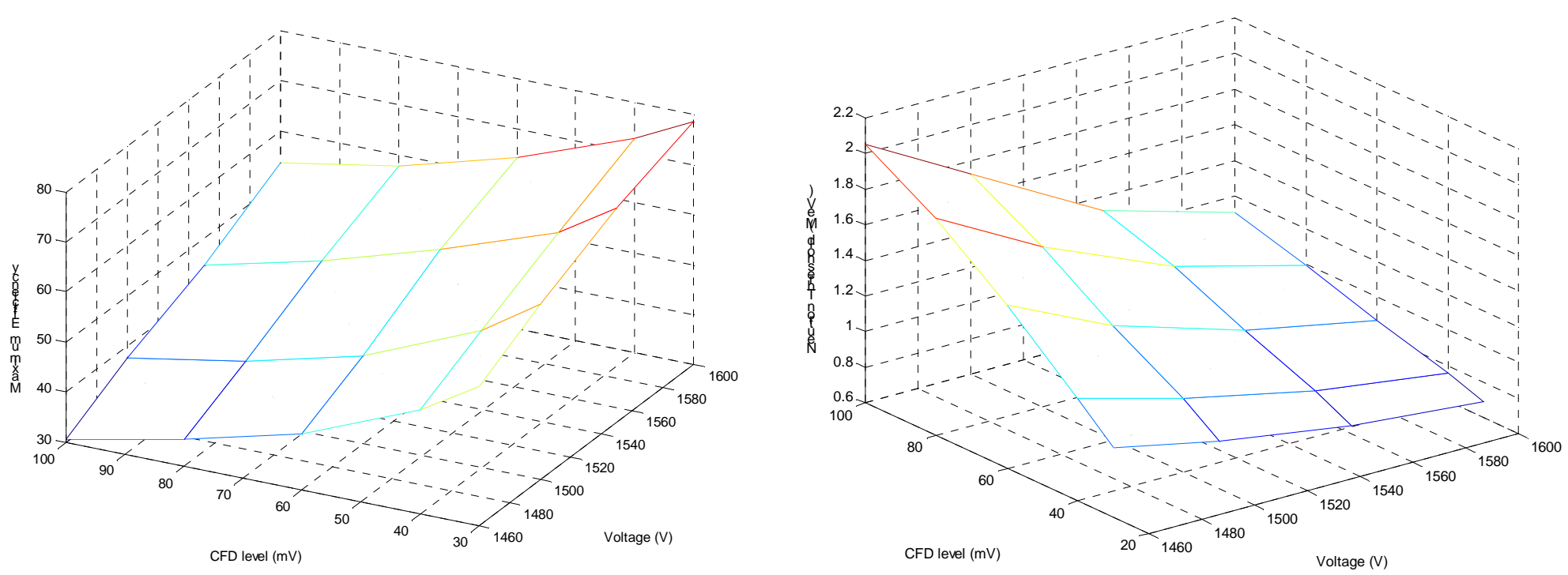

Figure A.4. Maximum neutron efficiency and neutron energy threshold as a function of CFD level ( $\mathrm{mV}$ ) and voltage (V). 


\section{Bibliography}

1. Chiang, Plutonium Test Plan: ORNL-VNIIEF Collaboration. Technical Report, Y/LB-16,061, Oak Ridge Y-12 Plant, 2000.

2. M. M. Chiles, J. T. Mihalczo, and C. E. Fowler. Small, Annular, Double-Contained ${ }^{252} \mathrm{Cf}$ Fission Chamber for Source-Driven Subcriticality Measurements. IEEE Transactions on Nuclear Science, 40(4):816, August 1993.

3. E. P. Ficaro. KENO-NR: A Monte Carlo Code Simulating the ${ }^{252} \mathrm{Cf}$-Source-Driven Noise Analysis Experimental Method for Determining Subcriticality. PhD thesis, University of Michigan, 1991.

4. G. E. Hansen, H. H. Helmick, and J. D. Orndorf. Neutron Counting Statistics in Basic Fast Critical Assemblies. In Joint Japan-United States Seminar on Reactor Noise Analysis, 1968.

5. N. W. Hill, J. T. Mihalczo, J. W. Allen, and M. M. Chiles. Optimization of Nanosecond Fission lon Chambers for Reactor Physics Applications. IEEE Transactions on Nuclear Science, NS-22:686, February 1975.

6. C. L. Hollas, C. A. Goulding, and W. L. Myers. Subcritical Neutron Multiplication Measurements of HEU Using Delayed Neutrons as the Driving Source. Technical Report, LA-UR-99-2192, Los Alamos National Laboratory, 1999.

7. C. March-Leuba and J. March-Leuba. Separation of Spatial Effects in FrequencyDomain Subcriticality Measurements. Annals of Nuclear Energy, 15(7):347-356, 1988.

8. J. K. Mattingly. Enhanced Identification of Fissile Assemblies Via Application of High Order Statistical Signatures. Technical Report, Y/LB-15,978, Oak Ridge Y-12 Plant, 1998.

9. J. K. Mattingly. High Order Statistical Signatures From Source-Driven Measurements of Subcritical Fissile Systems. PhD thesis, University of Tennessee, 1998.

10. J. K. Mattingly. High Order Statistical Signatures From Source-Driven Measurements of Subcritical Fissile Systems. Technical Report, Y/LB-15,966/R1, Oak Ridge Y-12 Plant, 1998.

11. J. K. Mattingly. Multivariate High Order Statistics of Measurements of the Temporal Evolution of Fission of Fission Chain-Reactions. Technical Report, Oak Ridge National Laboratory, 2001.

12. J. K. Mattingly, J. A. March-Leuba, J. T. Mihalczo, R. B. Perez, L. G. Chiang, T. E. Valentine, and J. A. Mullens. Passive NMIS Measurements to Estimate the Shape of Plutonium Assemblies. Technical Report, Y/LB-16,012, Oak Ridge Y-12 Plant, 1999. 
13. J. K. Mattingly, J. T. Mihalczo, J. A. March-Leuba, T. E. Valentine, R. B. Perez, J. A. Mullens, and L. G. Chiang. Passive NMIS Measurements to Estimate Shape of Plutonium Assemblies. In INMM 1998. Oak Ridge National Laboratory, November 1998.

14. J. K. Mattingly, J. T. Mihalczo, T. E. Valentine, J. A. Mullens, J. A. March-Leuba, and T. Uckan. Correlation Measurements With ${ }^{252} \mathrm{Cf}$ to Characterize Fissile Material. Technical Report, ORNL/TM-2000/3, Oak Ridge National Laboratory, 2000.

15. J. K. Mattingly, J. T. Mihalczo, T. E. Valentine, and R. B. Perez. Reduction of Background by Higher Order Correlations With NMIS. In 41st Annual Meeting, New Orleans, Louisiana, July 16-20, 2000. Institute for Nuclear Materials Management.

16. J. K. Mattingly, T. E. Valentine, and J. T. Mihalczo. NWIS Measurements for Uranium Metal Annular Castings. Technical Report, Y/LB-15,971, Oak Ridge Y-12 Plant, 1998.

17. J. T. Mihalczo. Use of ${ }^{252} \mathrm{Cf}$ as a Randomly Pulsed Neutron Source for Prompt Neutron Decay Measurements. PhD thesis, University of Tennessee, 1970.

18. J. T. Mihalczo. Use of Cf-252 as a Randomly Pulsed Neutron Source for Prompt Neutron Decay Measurements. Technical Report, Y-DR-41, UCC-ND, Oak Ridge Y-12 Plant, 1970.

19. J. T. Mihalczo. New Method for Measurement of the Effective Fraction of Delayed Neutrons From Fission. Nucl. Sci. Eng., 46:147, 1971.

20. J. T. Mihalczo, E. D. Blakeman, G. E. Ragan, E. B. Johnson, and Y. Hachiya. Dynamic Subcriticality Measurements Using the ${ }^{252} \mathrm{Cf}$-Source-Driven Noise Analysis Method. Nuclear Science and Engineering, 104:314-338, April 1990.

21. J. T. Mihalczo, E. D. Blakeman, G. E. Ragan, R. C. Kryter, H. Seino, and R. C. Robinson. ${ }^{252} \mathrm{Cf}$-Source-Driven Neutron Noise Measurements of Subcriticality for an Annular Tank Containing Aqueous Pu-U Nitrate. Nuclear Technology, 94:336-360, June 1991.

22. J. T. Mihalczo and N. W. Hill. Simple Time-of-Flight Transmission Measurement for Incorporation in Nuclear Engineering Curricula. Transactions of the American Nuclear Society, 14(1):60-61, 1971.

23. J. T. Mihalczo and W. T. King. Quality Assurance Verification of High-Flux Isotope Reactor Fuel Elements by the ${ }^{252} \mathrm{Cf}$-Source-Driven Noise Analysis Method. Nuclear Technology, 84:205-223, February 1987.

24. J. T. Mihalczo, W. T. King, and E. D. Blakeman. Subcriticality Measurements for Coupled Uranium Metal Cylinders Using the ${ }^{252} \mathrm{Cf}$ Source-Driven Neutron Noise Analysis Method. Nuclear Science and Engineering, 95:1-13, 1987.

25. J. T. Mihalczo. T. E. Koehler, T. E. Valentine, and L. D. Phillips. Source Options for Nuclear Weapons Identification System. Technical Report, ORNL/TM-13025, Oak Ridge National Laboratory, July 1995. 
26. J. T. Mihalczo, J. A. Mullens, J. K. Mattingly, and T. E. Valentine. Physical Description of Nuclear Materials Identification System (NMIS) Signatures. Nuclear Instruments and Methods, 450:531-555, August 2000.

27. J. T. Mihalczo and V. K. Paré. Theory of Correlation Measurement in Time and Frequency Domains With ${ }^{252} \mathrm{Cf}$. Annals of Nuclear Energy, 2:97, 1975.

28. J. T. Mihalczo, V. K. Paré, E. D. Blakeman, B. Damiano, L. D. Phillips, R. B. Bonner, D. B. Bopp, T. R. Chilcoat, J. DeClue, E. P. Elliott, G. D. Hackett, N. W. Hill, D. J. Nypaver, L. H. Thacker, W. T. Thomas, J. A. Williams, and R. E. Zumstein. NWIS Signatures for Confirmatory Measurements With B33 Trainers. Journal of Nuclear Materials Management, 25(3):64, 1997.

29. J. T. Mihalczo, V. K. Paré, G. E. Ragan, M. V. Mathis, and G. C. Tillett. Determination of Reactivity From Power Spectral Density Measurements With Californium-252. Nuclear Science and Engineering, 66:29-59, 1978.

30. J. T. Mihalczo and T. E. Valentine. Calculational Verification and Process Control Applications Utilizing the High Sensitivity of Noise Measurement Parameters to Fissile System Configuration. Nuclear Science and Engineering, 121:286-300, 1995.

31. J. T. Mihalczo, T. E. Valentine, and J. K. Mattingly. NWIS Methodology. Technical Report, Y/LB-15,953, Oak Ridge Y-12 Plant, 1997.

32. J. T. Mihalczo, T. E. Valentine, and L. D. Phillips. Subcritical Measurements for a HEU Storage Vault at the Y-12 Plant Using the ${ }^{252} \mathrm{Cf}-$ Source-Driven Frequency-Analysis Method. Nuclear Safety, 38(1):10-24, January-March 1997.

33. J. A. Mullens, J. K. Mattingly, T. E. Valentine, J. T. Mihalczo, and R. B. Perez. Incorporation of Neutron and Gamma Multiplicity Measurements in the ORNL Nuclear Materials Identification System (NMIS): Passive and Active Measurements. Technical Report, Y/LB-15,984, R2, Oak Ridge Y-12 Plant, October 1998.

34. C. L. Nikias and A. P. Petropulu. Higher-Order Spectra Analysis: A Nonlinear Signal Processing Framework. PTR Prentice-Hall, Inc., 1993.

35. R. B. Oberer. Maximum Alpha to Minimum Fission Pulse Amplitude for Parallel-Plate and Hemispherical Cf-252 Ion Chamber Instrumented Neutron Source. Technical Report, ORNL/TM-2000/290, Oak Ridge National Laboratory, September 2000.

36. V. K. Paré and J. T. Mihalczo. Reactivity From Power Spectral Density Measurements With Californium-252. Nuclear Science and Engineering, 56:213-218, 1975.

37. M. J. Paulus, J. T. Mihalczo, T. E. Valentine, J. A. Mullens, J. E. Breeding, T. Uckan, J. K. Mattingly, G. Turner, M. C. Smith, and J. A. McEvers. A Novel Method for Determining Pulse Counting Circuitry Dead Time Using the Nuclear Weapons Inspection System. IEEE Transactions on Nuclear Science, 45(3):710, June 1998. 
38. R. B. Perez, J. L. Muñoz-Cobo, T. E. Valentine, J. T. Mihalczo, and J. A. Mullens. Incorporation of Neutron and Gamma Multiplicity Measurements in the ORNL Nuclear Materials Identification System (NMIS): Passive and Active Measurements. In INMM 1999, July 1999.

39. M. Pitts. Design and Analysis of Subcritical Experiments Using Fresh Fuel Assemblies. PhD thesis, Georgia Institute of Technology, 1999.

40. S. A. Pozzi. Fast Time-Correlation Measurements in Nuclear Safeguards. PhD thesis, Politecnico di Milano, 2001.

41. J. A. Thie. Reactor Noise. Rowman and Littlefield, Inc., 1963.

42. R. Uhrig. Random Noise Techniques in Nuclear Reactor Systems. The Ronald Press Company, 1970.

43. T. E. Valentine, MCNP-DSP: A Neutron and Gamma Ray Monte Carlo Calculation of Source Driven Noise-Measured Parameters. PhD thesis, University of Tennessee, 1995.

44. T. E. Valentine. Evaluation of Prompt Fission Gamma Rays for Use in Simulating Nuclear Safeguard Measurements. Technical Report, ORNL/TM-1999/300, Oak Ridge National Laboratory, October 1999.

45. T. E. Valentine. Review of Subcritical Source-Driven Noise Analysis Measurements. Technical Report, ORNL/TM-1999/288, Oak Ridge National Laboratory, November 1999.

46. T. E. Valentine. MCNP-DSP: Monte Carlo N-Particle Transport Code System With Digital Signal Processing. Technical Report, CCC-699, Oak Ridge National Laboratory, October 2000. Radiation Safety Information Computational Center.

47. T. E. Valentine and J. T. Mihalczo. MCNP-DSP: A Neutron and Gamma Ray Monte Carlo Calculation of Source-Driven Noise-Measured Parameters. Ann. Nucl. Energy, 23(3):1271, 1996.

48. T. E. Valentine and J. T. Mihalczo. Validation of the Monte Carlo Code MCNP-DSP. Ann. Nucl. Energy, 24(2), 1997.

49. T. E. Valentine, J. T. Mihalczo, R. C. Kryter, and V. C. Miller. Subcritical Noise Analysis Measurements With Fresh and Spent Research Reactor Fuel Elements. Technical Report, ORNL/TM-13752, Oak Ridge National Laboratory, February 1999.

50. T. E. Valentine, J. T. Mihalczo, R. B. Perez, and J. K. Mattingly. Physics of the ${ }^{252} \mathrm{Cf}-$ Source-Driven Noise Analysis Measurement. Technical Report, CONF-970607-3, Oak Ridge National Laboratory, 1997.

51. T. E. Valentine, R. B. Perez, J. A. Mullens, and J. T. Mihalczo. Passive Multiplicity Counting With the Nuclear Materials Identification System for Plutonium. Technical Report, P99-104067, Oak Ridge National Laboratory, July 1999. 
52. Timothy E. Valentine. Evaluation of Prompt Fission Gamma Rays for Use in Simulating Nuclear Safeguard Measurements. Annals of Nuclear Energy, (28):191-201, 2001.

53. J. F. Zino. Design of a Pulse-Timing Based Subcritical Reactivity Measurement System for Spent Nuclear Fuel Assemblies. PhD thesis, Georgia Institute of Technology, 1999.

54. S. Pozzi, Milano, Italy, personal communication, 2000. 